\title{
REVIEW
}

\section{Does low-energy sweetener consumption affect energy intake and body weight? A systematic review, including meta- analyses, of the evidence from human and animal studies}

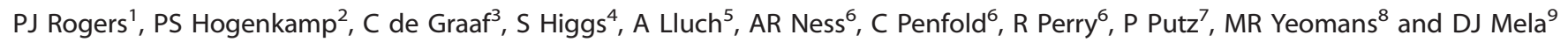

By reducing energy density, low-energy sweeteners (LES) might be expected to reduce energy intake (EI) and body weight (BW). To assess the totality of the evidence testing the null hypothesis that LES exposure (versus sugars or unsweetened alternatives) has no effect on El or BW, we conducted a systematic review of relevant studies in animals and humans consuming LES with ad libitum access to food energy. In 62 of 90 animal studies exposure to LES did not affect or decreased BW. Of 28 reporting increased BW, 19 compared LES with glucose exposure using a specific 'learning' paradigm. Twelve prospective cohort studies in humans reported inconsistent associations between LES use and body mass index $\left(-0.002 \mathrm{~kg} \mathrm{~m}^{-2}\right.$ per year, $95 \%$ confidence interval (Cl) -0.009 to 0.005). Meta-analysis of short-term randomized controlled trials (129 comparisons) showed reduced total El for LES versus sugarsweetened food or beverage consumption before an ad libitum meal ( $-94 \mathrm{kcal}, 95 \% \mathrm{Cl}-122$ to -66 ), with no difference versus water ( $-2 \mathrm{kcal}, 95 \% \mathrm{Cl}-30$ to 26). This was consistent with El results from sustained intervention randomized controlled trials (10 comparisons). Meta-analysis of sustained intervention randomized controlled trials (4 weeks to 40 months) showed that consumption of LES versus sugar led to relatively reduced BW (nine comparisons; $-1.35 \mathrm{~kg}, 95 \% \mathrm{Cl}-2.28$ to -0.42 ), and a similar relative reduction in BW versus water (three comparisons; $-1.24 \mathrm{~kg}, 95 \% \mathrm{Cl}-2.22$ to -0.26 ). Most animal studies did not mimic LES consumption by humans, and reverse causation may influence the results of prospective cohort studies. The preponderance of evidence from all human randomized controlled trials indicates that LES do not increase El or BW, whether compared with caloric or non-caloric (for example, water) control conditions. Overall, the balance of evidence indicates that use of LES in place of sugar, in children and adults, leads to reduced El and BW, and possibly also when compared with water.

International Journal of Obesity (2016) 40, 381-394; doi:10.1038/ijo.2015.177

\section{INTRODUCTION}

Low-energy sweeteners (LES), such as acesulfame-K, aspartame, saccharin, stevia and sucralose are consumed throughout the world. ${ }^{1}$ The history of their use has been accompanied by debate and disagreements, not least about their potential nutritional impact. The use of LES to replace or partially replace added sugar in foods and beverages might well be expected to reduce energy intake (EI), ${ }^{2-4}$ yet over recent years there has been widely reported speculation that consumption of LES might increase the risk of becoming overweight and obese. ${ }^{5-7}$

Studies covertly manipulating energy density show higher El after consumption of a reduced-energy food or beverage, but that the degree of energy 'compensation' is variable. ${ }^{8}$ Crucially, energy compensation is usually lower than the difference in energy content of the comparison foods/beverages, seemingly being lowest of all for liquids. ${ }^{8}$ This suggests that consuming LES in place of sugar-sweetened products should reduce overall El, and particularly so for consumption of beverages, the most popular vehicles for LES. ${ }^{1}$ The question also arises whether the presence of LES in beverages affects appetite and El relative to plain water. ${ }^{1,9}$
Although the imprecise control of short-term energy balance predicts that LES consumption should help reduce $\mathrm{El}$ and therefore reduce risk of overweight and obesity, ${ }^{3,10}$ it is possible that, as consumed in everyday life, other effects of LES balance or even outweigh the energy dilution effect. For example, a low calorie or 'diet' label may cause the consumer to eat a larger portion of the product or eat more of accompanying foods in the meal, or eat more later. ${ }^{11-14}$ More simply, adding sweetness to a product may increase intake owing to increased palatability. ${ }^{15,16}$ Or, by 'uncoupling' the relationship between sweetness and energy content, the consumption of LES may undermine the usefulness of sweetness as a cue in the control of energy balance. . $^{517-20}$

The effects of LES consumption on El and body weight (BW) have been the subject of many studies over the past 30 years; nonetheless there is no clear consensus about this body of evidence. Taken together, a number of narrative reviews ${ }^{1-4,21-25}$ and systematic reviews of some types of studies ${ }^{26-30}$ lead to the consistent but guarded conclusion that substitution of LES for sugar, especially in beverages, can help reduce $\mathrm{El}$, but that fully

\footnotetext{
${ }^{1}$ School of Experimental Psychology, University of Bristol, Bristol, UK; ${ }^{2}$ Department of Neuroscience, Uppsala University, Uppsala, Sweden; ${ }^{3}$ Division of Human Nutrition,

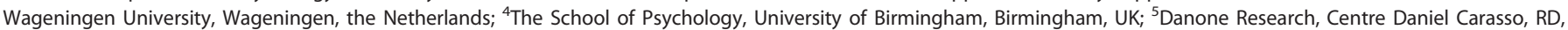

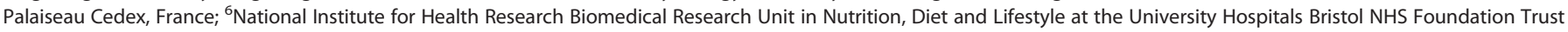
and the University of Bristol and School of Oral and Dental Sciences, University of Bristol, Level 3, University Hospitals Bristol Education Centre, Bristol, UK; ${ }^{7}$ European Branch, ILSI

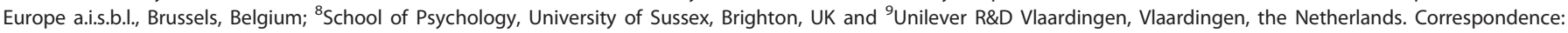
Dr P Putz, European Branch, ILSI Europe a.i.s.b.l., Avenue E. Mounier 83, Box 6, Brussels B-1200, Belgium. 
convincing evidence for longer-term beneficial effects is lacking. Our principle aim was, therefore, to bring together the totality of evidence to test the primary (null) hypotheses that LES consumption per se or as a replacement for caloric sweeteners in foods or beverages has no effect on El or BW outcomes in adults or children. We conducted systematic reviews of animal, human observational and human intervention studies providing information on LES consumption and $\mathrm{El}$ and/or BW. We included animal studies particularly because findings from a subset of animal studies appear to suggest that consumption of LES might increase risk of BW gain. ${ }^{19}$ Within the human intervention studies we furthermore sought to test a secondary (null) hypothesis that the effects of consumption of LES beverages on El and BW do not differ from the effects of consumption of water.

\section{MATERIALS AND METHODS}

A systematic search of the literature was undertaken to identify studies in humans and animals that assessed the effects of consumption of LES on El and/or BW and/or body mass index (BMI). LES were defined as ingredients contributing negligible energy to products to achieve a sweetness similar in comparison with caloric sweeteners. Thus LES include intense sweeteners and non-metabolized sugars but exclude most sugar alcohols (see Supplementary Information for full definition and examples). We use 'sugars' to refer to caloric sweeteners, usually sucrose.

The databases of MEDLINE and EMBASE via OVID interface and Web of Science were searched from their inception to 01 February 2015 , using a combination of MeSH terms and key word terms to identify research addressing the relevant combinations of exposures (sweetener types) and outcomes (describing food or $\mathrm{El}$, anthropometric measures or changes in these). No restrictions were applied regarding language or dates. This search generated 5506 articles, which were processed as summarised in Figure 1. Medline search terms and further details of our methods are provided in the Supplementary Information.

\section{ANIMAL STUDIES}

Study selection and data extraction

We identified 62 articles reporting a total of 90 eligible studies testing the effects of repeated consumption of LES on BW and/or El in non-human animals (rats or mice). These studies were divided into three sets based on their primary purpose. The first set investigated effects of long-term compulsory consumption of LES on BW and El often from primarily a toxicological perspective.

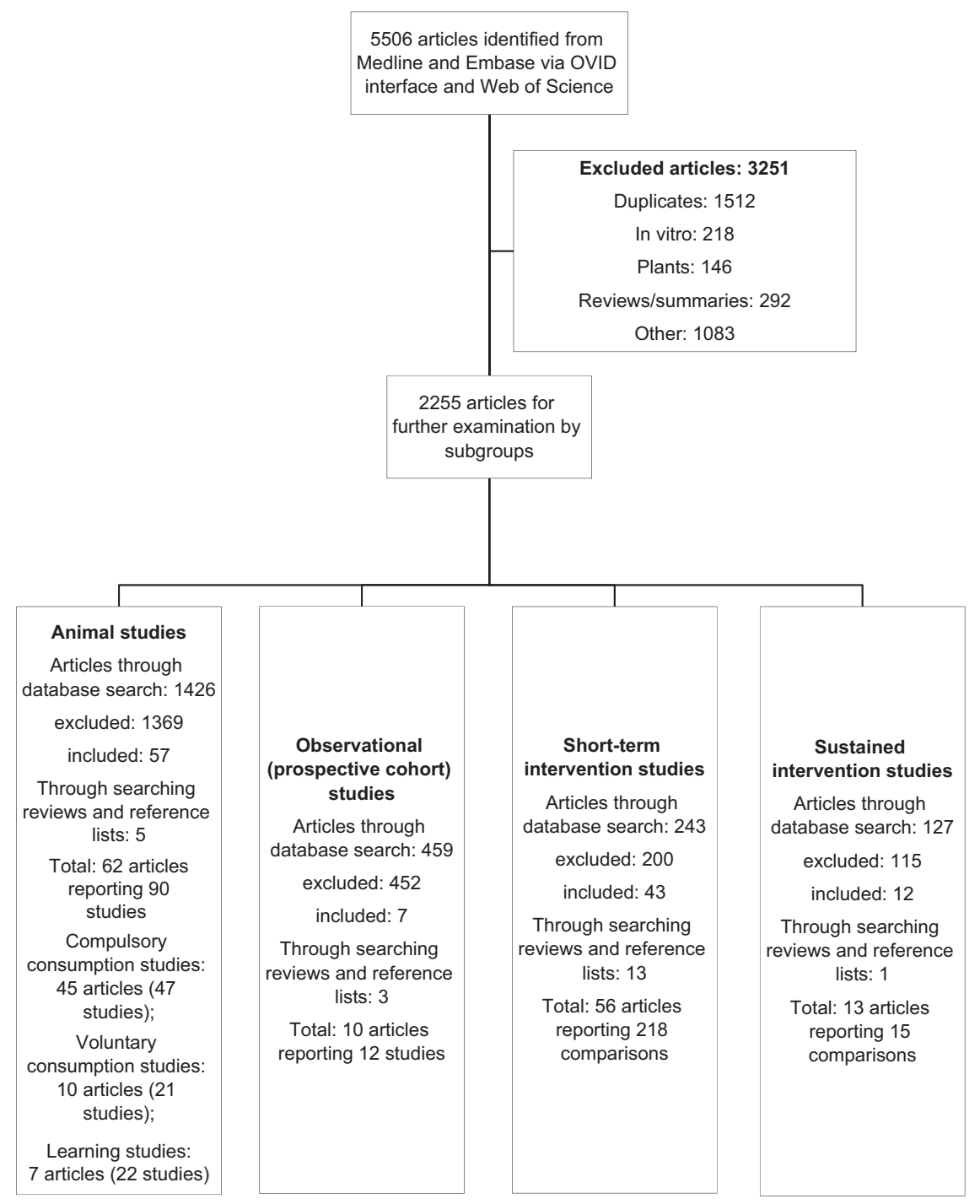

Figure 1. Flow of information through the different phases of the systematic review. 
The second set included a contrast of voluntary LES consumption usually as a sweetness-control in studies of effects of sugar on behaviour. The third set explored the hypothesis that LES can uncouple the predictive relationship between sweetness and $\mathrm{El}$ ('learning studies').

\section{Results}

Animal studies with compulsory consumption. There were 45 articles $^{31-75}$ reporting 47 studies examining changes in BW following at least daily compulsory consumption of LES (details in Supplementary Table S1). LES were either added to the animals' only source of food or water, or were orally intubated daily. The studies varied in LES (advantame, 2; aspartame, 4; cyclamate, 3 ; erythritol, 4; monatin, 2 ; neohesperidin, 2 ; oligo- $\mathrm{N}$-acetylglucosamine, 1; psicose, 2; saccharin, 8; stevia, 11; sucralose, 2; thaumatin, 1; combinations of LES, 8), species tested (mice, 12; rats, 35), exposure duration (3-104 weeks) and sample size (5-272). Although exact quantification of exposures is often difficult due to the use of water and food vehicles, comparison with human intakes ${ }^{76}$ indicates that most of the studies included dose ranges in excess of the equivalent amounts humans would consume. As a reference example, the upper acceptable daily intake values for saccharin and stevia in the European Union are 5 and $4 \mathrm{mg} \mathrm{kg}^{-1}$ per day, respectively, ${ }^{76,77}$ thus $<0.1 \%$ of the diet for a $70 \mathrm{~kg}$ human eating $500 \mathrm{~g}$ dry weight of food per day. The amounts of saccharin (1-7.5\% of diet by weight) and stevia ( $\geqslant 1 \%$ of diet by weight, and up to $2 \mathrm{~g} \mathrm{~kg}^{-1}$ per day) tested in most of these animal studies are at least 10 to 100 -fold greater. $^{32,34,39,44,47,52,56,57}$ The majority of studies, including all of the studies with larger sample sizes and/or longer durations of exposure, reported no statistically significant effects of LES on BW (Table 1). Eighteen studies of higher doses ( $>2 \%$ diet) found statistically significant decreases in BW, and in many of these studies this was reported in association with reductions in El. Only four of these studies reported statistically significant increases in BW. One of these reported increased BW with $1 \%$ saccharin in the diet although higher doses led to reduced BW. ${ }^{32}$ However, four further studies also using lower doses $(\approx 1 \%$ or less in diet) of saccharin found no statistically significant effects on BW. ${ }^{33,34,56,66}$ One study contrasting effects of adding saccharin, cyclamate, acesulfame-K or aspartame to the drinking water of mice reported significantly increased BW after saccharin and cyclamate. ${ }^{64}$ Another study also reported significantly increased BW (in rats) with a low-dose of cyclamate ${ }^{40}$ but this was not replicated in

Table 1. Outcomes of rodent studies providing information on effect of compulsory consumption of LES on BW

\begin{tabular}{|c|c|c|c|}
\hline & \multicolumn{3}{|c|}{ Change in BW relative to controls } \\
\hline & Decrease & No difference & Increase \\
\hline At any dose $(47)^{\mathrm{a}}$ & 22 & 21 & 4 \\
\hline Lower LES doses $(37)^{\mathrm{b}}$ & 4 & 32 & 1 \\
\hline Higher LES doses $(34)^{c}$ & 18 & 13 & 3 \\
\hline \multicolumn{4}{|c|}{$\begin{array}{l}\text { Abbreviations: BW, body weight; LES, low-energy sweetener. Figures are } \\
\text { numbers of studies reporting no difference or a significant change } \\
\text { (increase or decrease) in BW relative to controls, with total numbers of } \\
\text { relevant studies in brackets. Where a study used multiple LES doses (in } \\
\text { some studies including doses both below and above } 2 \% \text { of vehicle), if the } \\
\text { change in BW for any dose was significantly increased or decreased relative } \\
\text { to placebo, that result was counted as the effect of the LES overall. aAll } \\
\text { studies included in the count. 'bower LES doses, } \leqslant 2 \% \text { of vehicle (diet or } \\
\text { fluid source), only included in the count. 'Higher LES doses, }>2 \% \text { of } \\
\text { vehicle (diet or fluid source), only included in the count. }\end{array}$} \\
\hline
\end{tabular}

subsequent studies. ${ }^{37,41}$ Finally, in rats, addition of saccharin to an oil-enriched diet significantly reduced El and BW, whereas addition of saccharin to a diet enriched with beef tallow significantly increased El and BW. ${ }^{71}$

Animal studies with voluntary consumption. These studies (10 articles reporting 21 studies $^{78-87}$ ) examined effects of LES offered in water or food in addition to the usual diet (details in Supplementary Table S2). The largest group of these studies $(n=16)$ offered $0.1-0.2 \%$ saccharin solution as well as normal drinking water to rats for 2-3 weeks, with no statistically significant effects on BW, whereas addition of sucrose ${ }^{82,84,87}$ or polycose ${ }^{78,83}$ significantly increased BW in 7 out of 10 studies. The rats consumed $\approx 30 \mathrm{mg}$ of saccharin solution a day, equivalent to 40 times the human acceptable daily intake. Research that added saccharin to specific types of food found variable effects on BW. In a series of seven studies rats were fed wet mash (lab chow mixed with water) with saccharin added. ${ }^{86}$ In four out of five of these studies in which saccharin was added at the concentration of $0.2 \%$, the rats consumed significantly more food and gained BW significantly faster than did rats given unsweetened mash. These effects were similar to the effects of adding sucrose or fat to the diet. $^{86}$ There was no significant effect reported on BW in two studies in which a higher concentration of saccharin $(0.5 \%)$ was added to the additional food or when a saccharin solution was offered as well as drinking water. ${ }^{86}$ In a recent study, rats were given access to a diet supplement (yogurt) that had either sucrose, saccharin or aspartame added. ${ }^{80} \mathrm{~A}$ group receiving an unsweetened supplement was not included. Rats exposed to sucrose consumed less chow and gained less BW than did those exposed to the LES.

Learning studies. We identified seven articles, ${ }^{19,88-93}$ reporting 22 relevant studies, in which rats were exposed repeatedly on different days to two forms of a diet supplement: a sweetened version (either added glucose or LES) and a plain unsweetened version (details in Supplementary Table S3). The hypothesis under test was that, unlike rats exposed to a diet sweetened with glucose, rats exposed to a diet sweetened with LES will not learn that sweetness is associated with additional energy and as a result will have impaired ability to control intake of sweet food (specifically intake of their moderately sweet maintenance diet). Outcomes for all eligible studies were summarised in terms of whether there were statistically significant differences in BW and/ or El between LES and comparison conditions.

In 14 studies there was an increase in BW gain observed for the rats that had access to a LES-sweetened diet supplement, compared with those rats that had access to a glucosesweetened diet supplement. ${ }^{19,88-93}$ In three studies, there was no effect of the experimental manipulation on BW gain over time. ${ }^{91-93}$ In four studies the effect of LES exposure was found to be moderated by another factor such as sex, previous exposure to a high-fat diet, hormonal status or genetic proneness to obesity. ${ }^{92,93}$ In one study there was a significant day by sweetener interaction, but post hoc testing did not reveal a significant effect of sweetener exposure on any individual day. ${ }^{91}$

In one of the studies, a group was included that received a supplement (yogurt) sweetened with glucose on 3 days per week but no unsweetened supplement. ${ }^{89}$ This control group did not differ in BW gain from the group that received glucose-sweetened yogurt on some days and unsweetened yogurt on other days.

\section{Commentary}

A large majority of studies of compulsory and voluntary long-term consumption of LES by rodents found that LES did not increase BW. Only under certain conditions, perhaps where LES increased the palatability of specific diets, was increased BW observed. 
At higher doses of LES most studies found either no effect, or reduced $\mathrm{BW}$.

The results of the learning studies in rats suggest that intermittent exposure to a diet supplement sweetened with LES interweaved with exposure to the same non-sweetened diet can result in an increase in BW gain when compared with exposure to a glucose-sweetened diet. This has been replicated many times and, although there are some moderating factors, the effect appears robust. However, the relevance to usual human eating patterns remains unclear and specific hypotheses generated from these animal studies have yet to be tested directly in controlled studies with humans. The rats in these learning studies have limited dietary experience and, unlike humans who consume LES alongside sugar-containing foods, they do not have experience of consuming similar sweet tastes both with and without energy. Future research could assess the validity of the animal studies for human eating patterns by examining whether people who consume foods with the same taste but a range of energy densities, for example, sometimes eating regular versions and sometimes 'diet' versions of the same food, are more likely to overeat that food due to uncertainty about the energy delivered by that food. Until such tests have been conducted, continued speculation based on the results of these animal studies about the impact of LES use by people would seem unwarranted.

This review also suggests that the precise nature of the effects of LES on BW observed in these learning studies should be investigated further. In particular, more information is needed on BW gain in rats that receive a glucose-sweetened diet supplement on some days and an unsweetened diet supplement on other days compared with appropriate control groups (for example, rats exposed to only glucose-sweetened or only unsweetened diet supplements). This would determine whether or not exposure to glucose itself, rather than learning about the relationship between sweet taste and energy content, might account for differences in BW gain relative to rats exposed to LES intermittently.

\section{OBSERVATIONAL (PROSPECTIVE COHORT) STUDIES IN HUMANS}

Study selection and data extraction

Studies of over 500 participants that reported on prospective analyses with more than 1 year of follow-up were included. These studies had to report on LES beverages or LES intake as an exposure and BW or relative adiposity as an outcome. Studies that reported on LES consumption and metabolic syndrome but did not report separate associations for an anthropometric component of metabolic syndrome were excluded. Only one report of the results from each prospective study was included. Where there were several reports of the same study we included either the most detailed report of the results or the report with the longest follow-up. We did not include studies published only as an abstract. Our methods for data extraction are described in the Supplementary Information.

\section{Results}

We identified 10 articles reporting 12 studies $^{7,94-102}$ that met the eligibility criteria (details in Supplementary Table S4). All of the studies were carried out in the United States. The size of study population varied from 548 to $120877.6,100$ The latter article reported a combined analysis from three cohort studies with similar measures. Seven of the studies reported on adults $^{7,95,96,99,100}$ and five on children. ${ }^{94,97,98,101,102}$ All the studies used diet beverages as their exposure measure but reported a range of outcome measures. Follow-up ranged from one year ${ }^{94}$ to 20 years. $^{96}$

Five studies reported a higher risk of obesity associated with consumption of LES. ${ }^{7,94,96,99}$ The higher risk was present in boys but not girls in one of these studies, ${ }^{94}$ and was substantially attenuated after adjustment for dieting and parental weight concern in another study. ${ }^{102}$ Six studies reported a lower risk of obesity associated with consumption of LES..$^{95,98,100,101}$ In three of these studies there was only weak evidence against the null (no effect) hypothesis. ${ }^{95,98,101}$ One study reported a higher risk in girls but a lower risk in boys, though in both analyses there was limited evidence against the null hypothesis. ${ }^{97}$ The three largest studies were reported as a pooled analysis. ${ }^{100}$ In this pooled analysis there was evidence against the null hypothesis $(P=0.03)$. The effect size was modest $(0.10 \mathrm{~kg}$ BW reduction over a 4 -year period per serving per day of diet soda) with a wide $95 \%$ confidence interval $(\mathrm{Cl})(-0.14$ to $-0.06 \mathrm{~kg})$. We were able to combine data from 9 of the 12 studies ${ }^{7,94,95,97,100-102}$ in meta-analyses. In total there were six comparisons in adults and five in children. The random effects model (Figure 2) showed no change in BMI with LES consumption. However, there was a high level of heterogeneity among the studies. The fixed effect model showed a slightly lower BMI with LES consumption $\left(-0.008 \mathrm{~kg} \mathrm{~m}^{-2}\right.$ per year, $95 \% \mathrm{Cl}-0.010$ to -0.006 ) (Supplementary Table S5). An assessment of funnel plot asymmetry using Egger's regression test suggests there is weak evidence of asymmetry (Supplementary Figure S1 and Supplementary Table S6), meaning smaller studies may have been more likely to report an increase in BMI.

\section{Commentary}

In the 12 studies meeting our criteria, the associations reported were not consistent. Similar numbers of studies reported associations in each direction with respect to risk of BW gain or obesity. The largest studies reported a lower risk of obesity associated with consumption of LES, but the effect size was small. ${ }^{100}$ The random effects meta-analysis showed no change in BMI with consumption of LES.

Because the associations of interest may not have been a primary purpose of relevant studies, it is possible that our search strategies did not identify all articles that reported on LES as part of a report of the associations between diet and obesity. This omission would be more likely if the results were null and reported only as a line in the text. Nevertheless, the addition of another one or two studies, unless very large, would have limited effect on the present conclusions.

All the studies included in the review reported on the frequency of consumption of diet beverages and did not attempt to estimate consumption of LES in foods. Therefore, total intake of LES may not have been estimated accurately. It is possible that associations between 'diet' beverages and obesity represent confounding by other characteristics or behaviours of people who consume these beverages. Furthermore, people who are overweight or have a propensity to put on weight may consume 'diet' beverages in an attempt to lose weight or reduce weight gain. If reverse causality explained some or all of the association then adjustment for baseline BW or dieting or eating concerns would attenuate the association. This was the case in the analysis reported by Vanselow et al. ${ }^{102}$ Bias seems unlikely as this would imply that people using LES and with obesity will be more or less likely to be lost to follow-up. Generalisability is an issue as all the eligible studies were carried out in the United states, where diet beverages are commonly consumed and obesity prevalence is high.

The results from prospective studies of LES, BW and obesity are inconsistent. Observational studies are difficult to interpret as associations may be due to confounding or reverse causality. Even so, taken together there is little evidence from these studies to conclude that LES increase the risk of BW gain or obesity. 


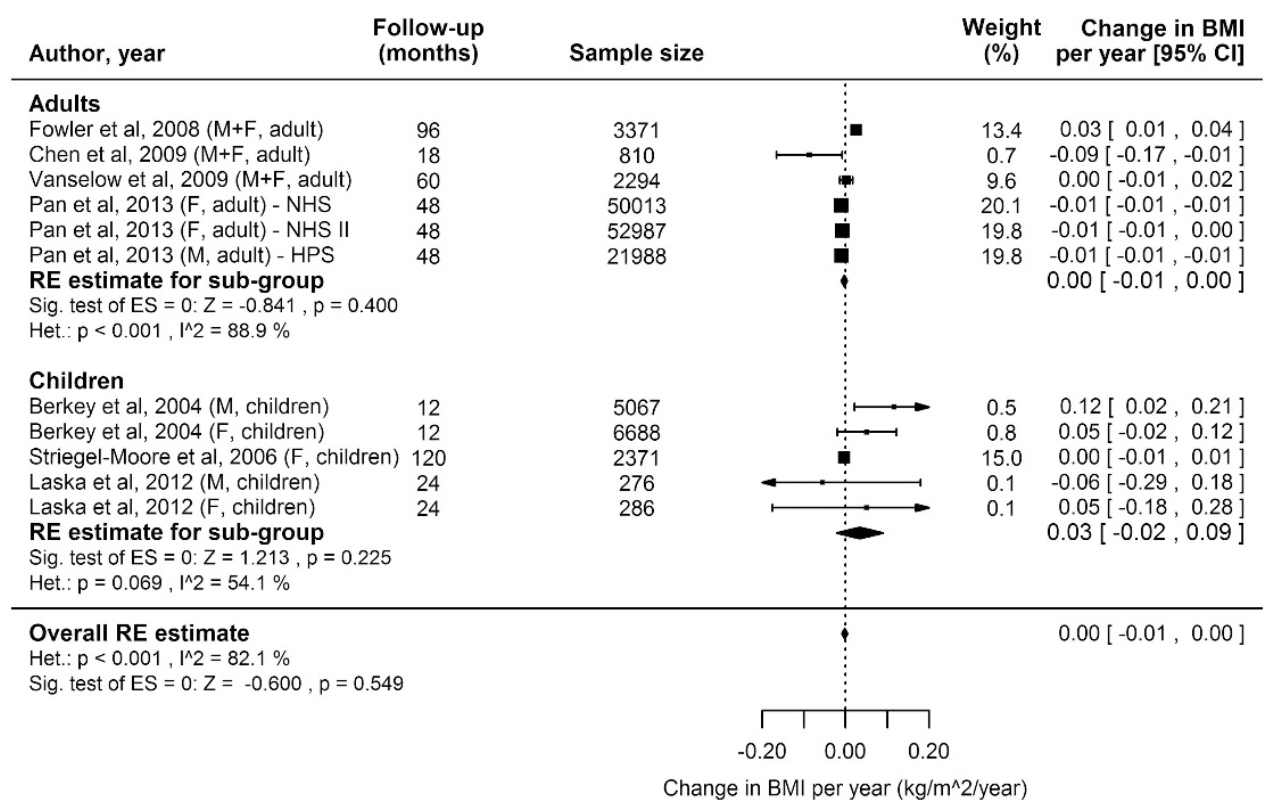

Figure 2. Forest plot showing individual and combined effect sizes for prospective cohort studies reporting the association between LES consumption and change in BMI over the follow-up period. Effect sizes have been standardised to a 1 year follow-up period. Negative scores favour LES consumption (BMI decrease). Squares represent change in BMI per year for the individual studies; square size is proportional to the weight of each study; horizontal lines represent $95 \% \mathrm{Cls}$. Diamonds represent the summary estimates and $95 \% \mathrm{Cls}$ from random effects models for associations in adults and children separately, and in adults and children combined. BMI, Body Mass Index; LES, low-energy sweetener.

\section{SHORT-TERM ( $\leqslant 1$ DAY) INTERVENTION STUDIES/RCTs}

Study selection and data extraction and analysis

Eligibility criteria for short-term intervention studies were: LES exposure of $\leqslant 24 \mathrm{~h}$ and El measured in an ad libitum meal (test meal) after consumption of the LES (preload) compared with a 'control' condition. We extracted data for test meal El after the LES preload and comparison preload(s), and for the energy content of the preloads. We also noted the preload-to-test meal interval, and the number of participants and their gender, and where available their age, BW and/or BMI, dieting and/or dietary restraint status.

We categorized the extracted data into five types of comparisons: LES versus sugar, LES versus unsweetened products, LES versus water, LES versus nothing and LES in capsules versus placebo capsules. We conducted meta-analyses to derive summary estimates of differences in cumulative El (preload plus test meal, kcal) separately for each of these types of comparison. For LES versus sugar comparisons we also derived summary estimates of compensation index (COMPX) scores. ${ }^{103}$ COMPX (EI in test meal after LES minus El in test meal after sugar)/(El from sugar preload minus El from LES preload) is expressed as percentage. It describes the extent to which adjustment in test meal intake 'compensates' for the difference in energy content of the LES versus sugar preload. If COMPX is $<100 \%$ then LES led to under-compensation (reduced cumulative EI), if COMPX $>100 \%$ then LES led to overcompensation (increased cumulative El), compared with sugar.

For LES versus sugar there was a good number of studies that tested children, so for this comparison we stratified the analysis by age group (child or adult participants). Fuller details of study selection, data extraction and statistical methods used are available in the Supplementary Information.

Results

We identified 56 eligible articles, ${ }^{83,104-158}$ which yielded a total of 218 comparisons. Of these, 118 were between LES and sugar (sucrose, glucose, fructose and mixtures of sugars including highfructose corn syrups). In a majority of the comparisons the participants were young, lean, low dietary restraint, non-dieting adults. The LES and sugar were most often given in a beverage (83\% of studies). Within individual comparisons, the sweetness of the LES and sugar preloads was similar.

Details of the studies are shown in Supplementary Tables S7-S11. The results of the meta-analyses are summarised in Figure 3, forest and funnel plots are shown in Supplementary Figures S2-S8, and results of meta-regression analyses are shown in Supplementary Table S12.

LES versus sugar. Cumulative (preload plus test meal) El was reduced with consumption of LES versus sugar preloads in adults and in children (Figure 3). The smaller absolute difference for children is partly accounted for by the lower energy content of the sugar preloads given to children compared with those given to adults. Children also showed somewhat greater compensation (COMPX score) than adults (Supplementary Figure S3). Compensation for the sugar preloads was $70 \%(95 \% \mathrm{Cl} 43$ to $97 \%)$ in children and $43 \%(95 \% \mathrm{Cl} 31$ to $55 \%)$ in adults, and significantly different from zero and from $100 \%$ in both groups. In other words, there was partial but not full compensation for the lower energy content of the LES compared with sugar preloads.

There was a high level of heterogeneity among the studies. A fully adjusted multivariable meta-regression model found no statistically significant associations of COMPX with year of publication, energy content of the sugar-containing preload or gender, and only weak evidence of an association with interval between preload and test meal (Supplementary Table S12). An assessment of funnel plot asymmetry using Egger's regression test suggests there is some asymmetry (Supplementary Figure S8 and Supplementary Table S6), meaning smaller studies may have been more likely to report larger COMPX scores. This bias may affect studies in children more than those in adults.

LES versus unsweetened, LES versus water and LES versus nothing. Cumulative El did not differ when a LES-sweetened preload was 


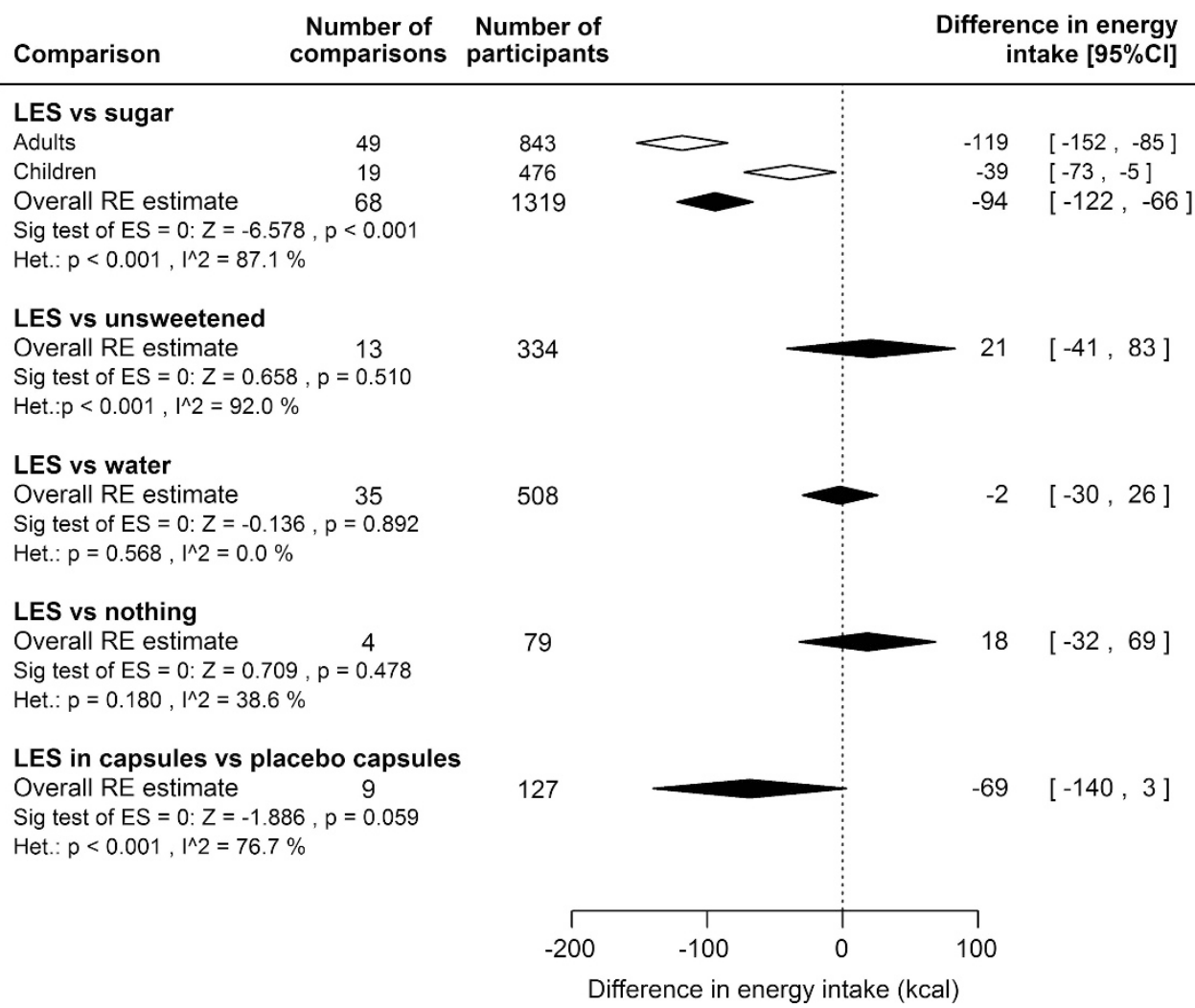

Figure 3. Summary of outcomes of meta-analyses of short-term intervention studies comparing the effects on El of LES versus sugar (for adults and children separately and combined), LES versus unsweetened products, LES versus water, LES versus nothing and LES in capsules versus placebo capsules. El difference is the difference in cumulative El (total of preload plus test meal EI) for the LES condition minus the comparison condition. Negative scores favour LES (that is, lower cumulative intake with LES). Filled diamonds represent the summary estimates and associated $95 \% \mathrm{Cls}$ from random effects models of all studies included in the comparison. Unfilled diamonds represent the summary random effects estimates and $95 \% \mathrm{Cls}$ for studies of adults and children separately. Many of the included studies reported multiple results for the same participants within the same comparison (for example, LES versus several different sugars). Treating these multiple results as independent potentially biases estimates of the variance of the summary effect sizes (see Supplementary Information methods section). Therefore, only the first set of results reported from each study was analysed. Accordingly, the total number of comparisons analysed (129) is less than the total recorded (218). El, energy intake; LES, low-energy sweetener.

consumed compared with when a preload of the same, but unsweetened product was consumed. Likewise, there was no difference in cumulative El with consumption of LES-sweetened beverages versus water and with LES-sweetened beverages versus nothing (Figure 3).

There was a high level of heterogeneity within these sets of studies, reflecting inconsistency in effect sizes, which is apparent in Supplementary Figures S4-S6. For LES versus water (the largest number of studies), multivariable meta-regression showed no clear associations between difference in cumulative El and gender, interval between preload and test meal, or year of publication (Supplementary Table S12). Egger's regression test and visual inspection of funnel plots indicate that bias is unlikely to have greatly affected these studies (Supplementary Table S6, Supplementary Figure S8), although this assessment is limited by the relatively small sample sizes of the studies and high heterogeneity.

LES in capsules. LES given in capsules compared with placebo capsules tended to reduce El (Figure 3 ). In all but one ${ }^{149}$ of the comparisons analysed the LES was aspartame. There was a high level of heterogeneity among studies. Multivariable metaregression indicated a potential association between the difference in cumulative El and the interval between the capsule and test meal. An interval of $>30 \mathrm{~min}$ compared with $\leqslant 30 \mathrm{~min}$ was associated with a decrease in El (Supplementary Table S12), although this finding may be unreliable due to the small number of comparisons analysed.

Sensitivity analyses. The sensitivity analyses (Supplementary Table S13) show that our summary effect sizes were unaffected by our estimates of unreported standard deviations, and fixed effect models (Supplementary Table S5) were broadly consistent with the main random effects models. Accounting for repeated measures on the same participants using robust variance estimation methods did not significantly alter the summary effect sizes.

\section{Commentary}

Taken together, these results show that consumption of LES in place of sugars is consistently found to reduce short-term El. Contrary to the concern that LES might increase intake acutely through stimulation of subsequent El by sweetness or via other mechanisms (reviewed in Mattes and Popkin ${ }^{1}$ ), El did not differ for LES versus water, LES versus unsweetened product or LES versus nothing. The high-observed heterogeneity in the effect sizes may be reasonably ascribed to methodological variations, only some of which could be assessed here. Preload size (difference in energy content), interval between preload and test meal, cross-over effects and nature of the test products, population and meal, have all been reported to influence absolute and relative (compensatory) El in these types of studies. ${ }^{8,148,159}$ 
A limitation of these studies is that they measure intake at a single meal only, so they may miss adjustments in intake that occur subsequently. Against this, our analysis showed, if anything, reduced compensation with increasing length of interval between consumption of LES and the meal (except for the capsule studies, which is not how LES are typically consumed). Another possible limitation is that almost all studies used cross-over designs. Evidence suggests that this causes the impact of disguised nutrient manipulations to be underestimated. ${ }^{148,160}$ This, however, may apply less to LES versus water comparisons. A further possibility is that on repeated exposure the perceived satiating effect of (and preference for) a LES-containing beverage or food will decrease relative its higher energy, sugar-containing counterpart. ${ }^{161-163}$ This again suggests that the sustained effect on El of LES versus sugar consumption may be less than is indicated by short-term (single exposure) studies.

Unlike in everyday life, the beverage or food in these studies was not presented with any explicit information (for example, 'diet' or 'low calorie') identifying either its energy content or the sweetener used. It would be counterproductive if dietary restraint were relaxed as a result of a perceived 'saving of calories' through consuming LES. 1,11,12,14,164 Only two articles addressed this particular issue. Neither found a difference in the effect of LES versus sugar on test meal El in participants who were informed about energy value of the preload compared with those who were not given this information. ${ }^{147,157}$

The studies comparing LES to unsweetened products, water or nothing suggest that the exposure to sweetness itself was not a significant stimulus for later El. However, the studies in which LES were consumed in capsules (in amounts similar to that contained in one or two portions of a LES-containing beverage) identify a reduction in El after aspartame that is not apparent for other LES. ${ }^{149}$ The mechanism for this effect is unknown ${ }^{156}$ but, more generally, these studies reduce the possibility that LES might increase appetite via stimulation of 'sweet taste' receptors in the gastrointestinal tract. ${ }^{1,165}$ Despite in vitro and animal research related to the physiological effects of gut sensing of nutrients and gustatory (mainly sweet or bitter) stimuli, LES appear to be generally weak stimuli for gut sensing in humans. ${ }^{166-168}$ This conclusion is supported by a large number of studies reporting only limited effects of various LES on glycaemic, insulinaemic and gut hormone responses. ${ }^{105,123,146,169-171}$ It is worth noting that, consistent with the suppressive effect on El of aspartame in capsules, repeated consumption of aspartame in capsules ( $2.7 \mathrm{~g}$ per day for 13 weeks) led to a $1.1 \mathrm{~kg}$ greater BW loss in young adults placed on an energy-restricted diet than did placebo capsules. ${ }^{172}$

In sum the results of these short-term studies comprise a large body of evidence showing that consumption of LES in place of sugar reduces overall El acutely, with no indication that LES increase appetite. They do not test the effect of repeated, sustained exposure to LES. This information is provided by longerterm intervention studies, which are reviewed next.

\section{SUSTAINED ( $>1$ DAY) INTERVENTION STUDIES/RCTs}

Study selection and data extraction and analysis

All studies with a LES exposure period of $>1$ day were classified as 'sustained' interventions. Studies were included only if (1) there was an explicit instruction or requirement to consume LESsweetened foods or beverages as an alternative to or substitute for consumption of sugar-sweetened products, water or habitual diet (the comparison treatment); (2) participants had ad libitum access to (other) dietary energy sources; and (3) reported end points included El and/or anthropometric measures. Studies furthermore had to have a parallel or balanced-ordered cross-over design with healthy participants (regardless of BW), who were either uninformed or correctly informed of the manipulation (not deceived). A study duration of $\geqslant 4$ weeks was applied as a further criterion for inclusion in a meta-analysis of LES effects on BW. As BW is the more reliable indicator of sustained effects on energy balance, no meta-analysis was undertaken for El. Assessments of risk of bias and methodological quality were also undertaken for these studies.

\section{Results}

Energy intake. There were nine studies comprising 10 comparisons and 1102 participants that reported El results. ${ }^{173-181}$ In all except one study ${ }^{181}$ the participants were adults, and all but four of the studies ${ }^{174,177,180,181}$ specifically recruited overweight or obese participants. In two studies ${ }^{173,179}$ the research was undertaken in the context of a weight loss programme. The duration of exposures was 10 days to $>1$ year. For all treatment comparisons (LES vs directly relevant controls) in all studies, the LES group had the lowest absolute values for total or change in El, compared with either sugar or water (Supplementary Table S14). The magnitude of the difference in intakes reported for LES vs non-LES interventions ranged from -75 to $-514 \mathrm{kcal}$ per day for comparisons with sugar, and $-126 \mathrm{kcal}$ per day in the single comparison with water. ${ }^{179}$

In three comparisons with 318 participants, the difference in total El was reported or determined to be statistically significant. ${ }^{176,177,181}$ In three comparisons with 293 participants the difference was not reported as statistically significant. ${ }^{173,175,178}$ In the remaining comparisons a direct test of statistical significance was not reported and could not be determined. ${ }^{174,179,180}$

Anthropometric. Twelve studies comprising 14 comparisons with 1941 participants reported anthropometric data, ${ }^{173-180,182-185}$ in most cases only BW. This total excludes 67 intentionally misinformed participants in Reid et al. ${ }^{177}$ The duration of exposures was 10 days to $>3$ years, and participants in all studies were adults except for those in de Ruyter et al. ${ }^{182}$ All except four studies $^{175,177,180,182}$ specifically recruited overweight or obese participants, and four studies ${ }^{173,179,183,185}$ carried out the interventions in the context of a weight loss programme. Details of these studies are shown in Supplementary Table S14. The results of the meta-analyses of the 10 studies (12 comparisons) of $\geqslant 4$ weeks in duration are shown in Figure 4.

In all comparisons the LES intervention produced the smallest absolute gain or largest absolute loss of BW, compared with either sugar or water. In six comparisons with 1274 participants, anthropometric differences favoring LES were reported to be statistically significant. ${ }^{173,176,177,180,182,185}$ In eight comparisons with 667 participants the differences were not reported as statistically significant. ${ }^{175,176,178,179,183,184}$

The main meta-analysis of BW change comparing sustained use of LES vs sugar-sweetened products is based on eight comparisons with 691 adults and one comparison with 641 children. In our random effects model we found a relative BW loss in adults using LES products compared with sugar-sweetened products (Figure 4). In the only study with children there was a comparable effect size and same direction of effect, so the overall random effects model (adult and child studies combined) also found that participants who consumed LES products compared with sugarsweetened products showed relative reductions in BW (greater loss or less gain) (Figure 4).

There was a high degree of heterogeneity among the studies, which arises from differences in the magnitude and not direction of effect, which was consistent across all studies. The overall estimates and measure of heterogeneity were little changed by removal of the one study with children. A multivariable metaregression model of change in BW on gender (studies with males 


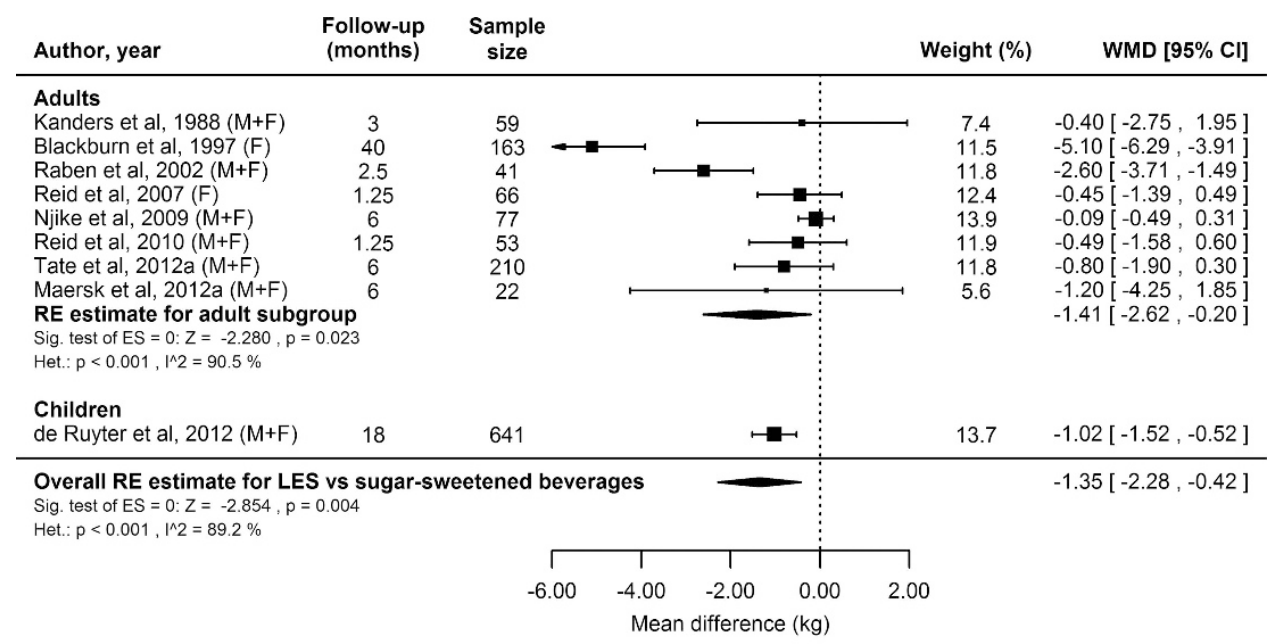

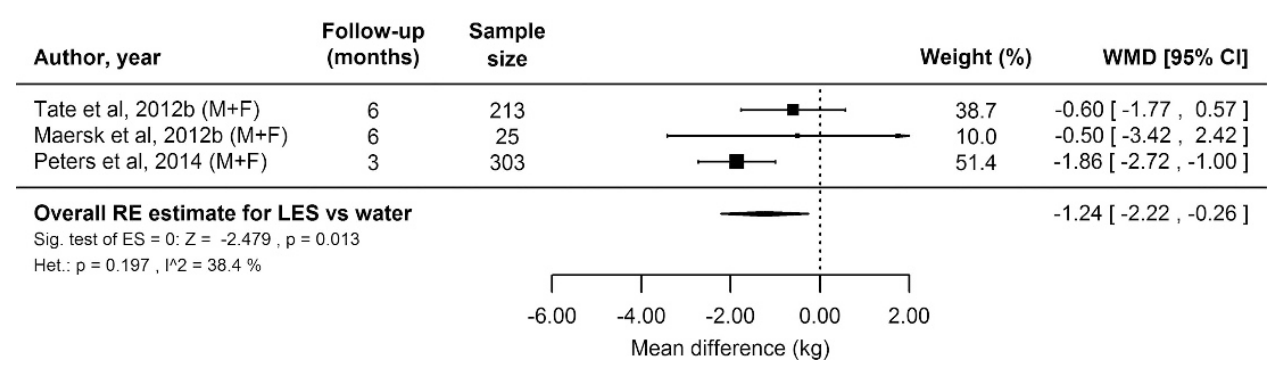

Figure 4. Forest plots showing individual and combined effect sizes for sustained intervention studies comparing the effects on BW of LES versus sugar (upper panel) and LES versus water (lower panel). Mean difference is weight change (end point minus baseline) in the LES condition minus weight change in the sugar condition over the intervention period (a negative score favours LES). Squares represent mean difference in BW for the individual comparisons; square size is proportional to the weight of each comparison; horizontal lines represent $95 \%$ $\mathrm{Cls}$; diamonds represent the summary estimates and $95 \% \mathrm{Cls}$ from random effects models for comparisons in adults for LES versus sugar, adults and children for LES versus sugar, and adults for LES versus water. BW, body weight; LES, low-energy sweetener.

only, females only or both), BW category (all weights, overweight and obese only or obese only) and length of follow-up suggested these study characteristics are not important sources of heterogeneity (Supplementary Table S15). Egger's regression test (Supplementary Table S6) and visual inspection of funnel plots (Supplementary Figure S9) suggest that small-study bias is unlikely to be present. However, these assessments of bias and sources of heterogeneity are limited by the small number of studies and high level of heterogeneity.

The secondary meta-analysis of BW change using LES products versus water was based on three comparisons with 541 adults. The random effects model indicates a statistically significant reduction in BW in adults using LES products compared with water, with an effect size only slightly smaller than that observed for comparisons with sugar-sweetened products (Figure 4).

Sensitivity analyses suggested that using imputed standard deviations did not substantially alter the outcomes of the analyses (details in Supplementary Table S16).

The results of the 'risk of bias' and 'methodological quality' assessments are summarised in Supplementary Tables S17 and S18. They highlight that full blinding of the interventions (for participants and some personnel) was not possible in many studies. However, most papers also did not explicitly state whether outcome assessors were blinded to the interventions, or the methods of randomisation and allocation. Furthermore, there was inconsistent reporting of the nature of dropouts, and some studies only reported on participants fully completing the treatment $\operatorname{arm}(\mathrm{s})$ despite significant (>10\%) dropouts.

\section{Commentary}

Although these sustained intervention studies vary in design and quality, and several were not primarily intended to test effects of consumption of LES, the results are nevertheless consistent. In all cases, the use of LES led to a relative reduction in El, and greater loss (or reduced gain) of BW. Notably, there was no example of a sustained exposure intervention trial where LES use led to a relative increase in mean El or BW. This was supported quantitatively by the results of the meta-analyses of BW change, indicating lower relative BWs in LES intervention arms. Furthermore, outcomes were similar in studies with children and adults, and followed a similar pattern whether participants were blinded or not blinded to the intervention. Consumption of LES-sweetened beverages also reduced BW relative to consumption of water.

In addition to the studies meeting the criteria for inclusion here, there are also studies in adults and children where LES were a component of a mixed or more complex diet or lifestyle manipulation. ${ }^{95,186-190}$ Although these other studies provide only indirect evidence, their results were consistent with the 'pure' LES interventions; that is, treatments that included LES were associated with reductions or no change in El or BW. No example was found where an intervention specifically including LES led to a relative increase in $\mathrm{El}$ or $\mathrm{BW}$.

Taken at face value, these results show that consumption of LES compared with sugar leads to either no change or a relative reduction in El and energy balance. More unexpectedly, however, LES also led to reductions in BW relative to water. There are, however, some possible limitations to this evidence base to consider. 
Table 2. Summary of the results of the review

Type and number of studies (or number of comparisons) ${ }^{a} \quad$ Results

Animal studies, 90

BW gain when LES added to food or drink compulsorily or voluntarily consumed compared with BW gain on the food or drink without LES: $22 \downarrow 37 \rightarrow 9 \uparrow$ BW gain when LES added to a dietary supplement compared with BW gain when glucose added to the same dietary supplement: $0 \downarrow 3 \rightarrow 19 \uparrow$

Prospective cohort studies, 12 No overall association of LES consumption with BMI

Short-term intervention studies (129 comparisons analysed ${ }^{\mathrm{b}}$ )

El from preload plus ad libitum meal when preload was LES versus sugar, unsweetened food, water, nothing or placebo capsule:

LES $<$ sugar (children and adults)

LES = unsweetened

LES $=$ water

LES $=$ nothing

LES in capsule $<$ placebo capsule (trend)

Sustained intervention studies,

El (10 comparisons)

In all cases the absolute value for total or change in El was lower for LES:

LES versus sugar -75 to $-514 \mathrm{kcal}$ per day (nine comparisons)

LES versus water $-126 \mathrm{kcal}$ per day (one comparison)

Sustained intervention studies $\geqslant 4$ weeks in duration,

Difference in weight loss or weight gain favoured LES:

LES versus sugar $-1.41 \mathrm{~kg}$ (adults, eight comparisons)

LES versus sugar $-1.02 \mathrm{~kg}$ (children, one comparison)

LES versus water $-1.24 \mathrm{~kg}$ (adults, three comparisons)

Abbreviations: BMI, body mass index; BW, body weight; El, energy intake; LES, low-energy sweeteners. $\downarrow$ decrease; $\rightarrow$ no difference; $\uparrow$ increase. ${ }^{a}$ Some studies had more than one relevant comparison, for example LES versus sugar and LES versus water, or LES versus sugar in lean participants and LES versus sugar in overweight participants reported separately. ${ }^{\text {b }}$ See caption to Figure 3.

First, most protocols ${ }^{175-180,182,184}$ required participants to consume some amount of test products with LES or sugar. If the latter constitute an energy supplement to the diet, and if adding energy to the diet tends to be poorly compensated, ${ }^{191,192}$ this design will overestimate the benefit of LES. However, similar outcomes were observed where participants were recruited on the basis of already regularly consuming sugar-sweetened products, where the intervention was replacement of those by LES. ${ }^{179,182}$ Thus, both 'supplementation' and 'substitution' interventions lead to similar conclusions.

Second, in most comparisons of LES with sugars ${ }^{174-176,180-182,184}$ participants were blind to the intervention. This does not model the 'real-world' consumption of such products, where consumers are usually aware of choosing a LES-sweetened ('diet') or sugarsweetened product. In this situation, awareness of reductions in El from LES products may be mitigated by relaxed restraint towards consumption of energy from other items in the diet. Against this, results of blinded studies did not differ appreciably from comparisons with sugar (or water) where participants were aware of the nature of the intervention products. ${ }^{173,177,179,183-185}$ This is consistent with the short-term intervention studies and two studies of 4 weeks duration, which reported no effect of participants being specifically informed or misinformed as to beverages being LES or sugar-sweetened. ${ }^{177,178}$ Thus, the evidence indicates that effects of LES on EI or BW are probably not markedly affected by awareness.

Third, the comparison of LES with water is based on only three studies. ${ }^{179,184,185}$ Of these, two were large studies carried out in a BW loss context, in which participants who habitually consumed either sugar- ${ }^{179}$ or LES- ${ }^{185}$ sweetened beverages were assigned to consume water.

BW differences were greatest in the longest study, which lasted 40 months, ${ }^{173}$ as can be seen in Figure 4, although there is no clear relationship between study duration and BW loss among the other studies in adults (duration 1.25-6 months). Together the studies included males and females, and lean, overweight and obese participants. We found no evidence that gender or BW status affected the outcome of the intervention, indicating that the effects of consuming LES versus sugar-sweetened are general, rather than specific to certain groups of individuals. Similarly, the recent large study by de Ruyter et al. ${ }^{182}$ is significant in that it shows an impact on BW of LES versus sugar consumption in children. Indeed, the effect in this study in favour of LES was close in size to the combined effect size for the studies in adults (Figure 4).

\section{DISCUSSION}

Table 2 summaries the results of this review. It shows that the weight of the evidence indicates decreased El and BW with consumption of LES relative to sugar. Furthermore, LES do not appear to increase El, and in human interventions studies tend to lead to a relatively decreased BW, even compared with consumption of water in the groups tested. These findings are consistently contrary to the concern that has been raised by some authors ${ }^{5-7}$ that consumption of LES may increase risk of becoming overweight and obese. The results in favour of a benefit of LES use in BW management come primarily from a substantial number of short-term and sustained intervention studies testing human participants, which can be reasonably said to rank above observational studies and animal studies as sources of evidence for informing health-care decisions, including dietary recommendations. In any case, close examination of the totality of the evidence including that from observational and animal studies does not contradict the conclusion that LES use is helpful, or at least neutral, with respect to BW control.

A recent systematic review and meta-analysis of the evidence from prospective cohort and sustained intervention studies on LES and BW and composition ${ }^{193}$ differs from ours in the studies included and excluded for both sources of evidence (see Supplementary Tables S19 and S20 for further details), and in not considering the evidence from short-term intervention studies and animal studies, or the specific comparison with water. The authors, nevertheless, reach similar conclusions to us. They state that 'substituting LCS (lowcalorie sweeteners) options for their regular-calorie versions results in modest BW loss, and may be a useful dietary tool to improve compliance with BW loss or BW maintenance plans'. ${ }^{193}$

We found that prospective associations between LES consumption and BW change were not consistent across the literature, with beneficial and adverse associations of LES use with BW reported by similar numbers of studies. This could be due to differences in 
the populations studied and/or the extent to which specific confounding factors were accounted for, chance findings in small studies and publication bias. A major confounder may be the BW control history and strategies used in the different populations. Thus, reverse causation cannot be ruled out. Notably, though, pooled analysis of the three largest studies showed a relative BW reduction for those consuming LES. ${ }^{100}$

Evidence from a large majority of animal studies favours reduced $\mathrm{El}$ and $\mathrm{BW}$ gain or no effect of LES, although increases have been observed as well. A particular series of studies from one research group employing a specific procedure in rats has been widely cited in support of the suggestion that consumption of LES could lead to BW gain. ${ }^{194}$ The mechanism proposed for this is that LES consumption disrupts learning about the association between sweet taste and energy content. Arguably, however, the complexity of modern human diets is such that sweetness, with or without the inclusion of LES, does not reliably predict energy content foods. ${ }^{195}$ More likely, what is learned, if anything, is energy content (and its satiating effect) signalled by a configuration of taste, flavour, texture and other cues specific to individual foods. Therefore, whether or not LES are consumed will likely make little difference to the learned control of El. In any case, without information from further control groups the interpretation of the results of these studies is ambiguous. Their relevance to human consumption of LES therefore remains to be demonstrated, especially in the light of the evidence from sustained human intervention studies of reduced BW with consumption of LES versus sugar, and LES versus water. In general, the animal studies did not mimic the use of LES by humans, either in amounts consumed or pattern of consumption.

A variety of human and animal intervention studies provided data on the effects of consumption of LES-sweetened liquids versus water. The results indicate that the exposure to sweetness itself (without energy) is at least neutral in terms of impact on $\mathrm{El}$ and energy balance, and possibly even helpful. This challenges the suggestion that exposure to sweetness itself is detrimental, 6,196,197 perhaps because exposure to sweetness could help 'establish and maintain' a more generalised preference for sweet items. ${ }^{1}$ Acquired preferences for sweetness levels are relatively foodspecific, although this is expressed against the background of a general innate liking for sweetness. ${ }^{198}$ On the other hand, evidence from studies of 'sensory-specific satiety' show that acute exposure to sweetness decreases subsequent desire for the same or other sweet (relative to non-sweet) items. ${ }^{199-201}$ Consistent with this, participants in the CHOICE trial receiving LES beverages specifically reduced consumption of dessert items relative to those receiving water. ${ }^{202}$ One possible interpretation is that access to LES satisfies a pre-existing desire for sweetness, rather than promoting it.

A further result is that LES consumed in capsules either had no effect or reduced El in short-term intervention studies (Figure 3), which argues against stimulation of gut receptors as a route by which LES might contribute toward increased El and BW.

The short-term intervention studies in humans measured the effects of consuming a fixed portion of a LES-sweetened beverage or food on free (ad libitum) consumption of other items presented in the test. In many of the animal studies the manipulated food was also the food that was consumed freely. For the most part the results of these two types of study lead to the equivalent conclusion, namely that there was little effect of the LES versus the equi-caloric control (usually water in the human studies, and unsweetened food in the animal studies) on $\mathrm{El}$ or BW. An exception is increased $\mathrm{El}$ and $\mathrm{BW}$ gain in a small number of studies in which saccharin was added to moistened or fat-enriched diets, perhaps owing to saccharin increasing the palatability of these diets. This context differs from the consumption of LES in the human diet, where LES usually replace sugars in foods and beverages. ${ }^{1}$ Furthermore, as discussed above, there is no substantive evidence that consuming LES-sweetened products increases El or BW in humans.

Our analysis of short-term intervention studies comparing LES with water supports Daniels and Popkin's ${ }^{27}$ conclusion that these studies are 'relatively consistent and found no impact on El among adults' (p 505). Their review of a subset of the studies we included found that consumption of water versus LES-sweetened beverages led to essentially no change ( $1.3 \%$ reduction) in El in adults and a $6.7 \%$ reduction in children. Nevertheless, our meta-analysis of three sustained intervention studies with a water comparison finds that LES consumption leads to somewhat reduced BW relative to consumption of water. ${ }^{179,184,185}$ As well as an effect via 'sensory-specific satiety' (above), this perhaps suggests an advantage for LES in respect of dietary compliance, in that LES beverages may be preferred to water. ${ }^{179}$ It would seem appropriate therefore to consider, particularly for consumers already accustomed to sweetened beverages, whether promotion of LES or water as an alternative holds greatest public health effectiveness. $^{203}$ The answer should come from further appropriately designed intervention studies and perhaps further analyses of already completed trials where participants had free choice of water versus LES beverages. ${ }^{187}$

Both short-term and sustained intervention studies in humans show LES consumption reduces ad libitum El. However, possibly for several reasons, short-term studies may underestimate the degree of energy compensation that occurs in response to energy dilution. This is consistent with the finding that BW differences observed in sustained intervention studies are often much smaller that would be the case if no compensation had occurred. ${ }^{182}$ Nonetheless, sustained studies repeatedly find effects in favour of LES consumption reducing BW relative to sugar consumption, showing that compensation is incomplete. Of course, the same argument and many of the same data are used in making the case that consumption of sugar-sweetened products, and particularly sugar-sweetened-beverages, increase risk of overweight and obesity. ${ }^{182,204,205}$

\section{CONCLUSIONS}

We found a considerable weight of evidence in favour of consumption of LES in place of sugar as helpful in reducing relative $\mathrm{El}$ and $\mathrm{BW}$, with no evidence from the many acute and sustained intervention studies in humans that LES increase El. Importantly, the effects of LES-sweetened beverages on BW also appear neutral relative to water, or even beneficial in some contexts.

A selection of animal and observational studies is often cited as the primary basis for strong assertions that LES are a contributing factor toward risk of overeating and obesity. ${ }^{5}$ In contrast, the present review of a large and systematically identified body of evidence from human intervention studies, with varying designs, settings and populations (including children and adults, males and females, and lean, overweight and obese groups), provide no support for that view. The question then is whether those hypotheses should be rejected or whether, as seems unlikely, the relevant human intervention studies are consistently flawed in a way that leads, in most cases, to exactly the opposite outcome.

Commentaries on LES and energy balance frequently suggest that further research is needed, but stop short of proposing any specific new hypothesis to test or new study designs. Although no single study by itself is conclusive, the correspondence of results from the studies reviewed here gives no reason to expect another similar study would yield remarkably different results. Continued selective citation and extrapolation from observational and animal studies on this topic is also likely to be of limited value. Mattes \& Popkin ${ }^{1}$ concluded that replacement of sugar by LES has 'the potential to aid in BW management, but whether they will be used in this way is uncertain' ( $p$ 10). This seems a reasonable conclusion 
from the literature, and shifts the issue from whether LES are 'good' or 'bad,' and re-focuses it on the question of how they are best used in practice to help in the achievement of specific public health goals, such as the reduction of intakes of free sugars and energy.

\section{CONFLICT OF INTEREST}

Peter J Rogers has received grants from Sugar Nutrition, UK in support of research on the effects of sugar on human appetite. Cees de Graaf has received grants from the Dutch Sugar Bureau in support of a study on brain responses to sugars and low energy sweeteners. Suzanne Higgs has received a grant from Canderel in support of research on the effects of low-energy sweeteners on human appetite. Anne Lluch and David J Mela are employees and shareholders of companies that manufacture products containing sugars and low-energy sweeteners. Peter Putz is an employee of ILSI Europe. The remaining authors declare no conflict of interest.

\section{ACKNOWLEDGEMENTS}

This work was conducted by an expert group of the European branch of the International Life Science Institute (ILSI Europe). The expert group received funding from the ILSI Europe Eating Behaviour and Energy Balance Task Force. Industry members of this task force are listed on the ILSI Europe website at www.ilsi.eu. For further information about ILSI Europe, please e-mail: info@ilsieurope.be or call +32 2 77100 14. The opinions expressed herein and the conclusions of this publication are those of the authors and do not necessarily represent the views of ILSI Europe, nor those of its member companies and the authors affiliations. Part of the research leading to this review received funding from the European Union Seventh Framework Programme for research, technological development and demonstration under grant agreement no. 607310 (PJR). The contributions of Andy R Ness, Christopher Penfold and Rachel Perry were supported by the National Institute for Health Research Bristol Nutrition Biomedical Research Unit based at University Hospitals Bristol NHS Foundation Trust and the University of Bristol. The authors would like to thank Dr Sanne Griffioen-Roose (then at Wageningen University) for her contribution at an early stage of this review, and ILSI Europe staff for their invaluable support in keeping this project on track and in the preparation of the manuscript.

\section{REFERENCES}

1 Mattes RD, Popkin BM. Nonnutritive sweetener consumption in humans: effects on appetite and food intake and their putative mechanisms. Am J Clin Nutr 2009; 89: $1-14$.

2 Drewnowski A. Intense sweeteners and energy density of foods: implications for weight control. Eur J Clin Nutr 1999; 53: 757-763.

3 Bellisle F, Drewnowski A. Intense sweeteners, energy intake and the control of body weight. Eur J Clin Nutr 2007; 61: 691-700.

4 Anderson GH, Foreyt J, Sigman-Grant M, Allison D. The use of low-calorie sweeteners by adults: impact on weight management. $J$ Nutr 2012; 142: 1163S-1169S.

5 Swithers SE. Artificial sweeteners produce the counterintuitive effect of inducing metabolic derangements. Trends Endocrinol Metabol 2013; 24: 431-441.

6 Ludwig DS. Artificially sweetened beverages: cause for concern. JAMA 2009; 302: 2477-2478.

7 Fowler SP, Williams K, Resendez RG, Hunt KJ, Hazuda HP, Stern MP. Fueling the obesity epidemic? Artificially sweetened beverage use and long-term weight gain. Obesity 2008; 16: 1894-1900.

8 Almiron-Roig E, Palla L, Guest K, Ricchiuti C, Vint N, Jebb SA et al. Factors that determine energy compensation: a systematic review of preload studies. Nutr Rev 2013; 71: 458-473.

9 Popkin BM, Armstrong LE, Bray GM, Caballero B, Frei B, Willett WC. A new proposed guidance system for beverage consumption in the United States. Am J Clin Nutr 2006; 83: 529-542.

10 Levitsky DA, Obarzanek E, Mrdjenovic G, Strupp BJ. Imprecise control of energy intake: absence of a reduction in food intake following overfeeding in young adults. Physiol Behav 2005; 84: 669-675.

11 Shide DJ, Rolls BJ. Information about the fat content of preloads influences energy intake in healthy women. J Am Diet Assoc 1995; 95: 993-998.

12 Miller DL, Castellanos VH, Shide DJ, Peters JC, Rolls BJ. Effect of fat-free potato chips with and without nutrition labels on fat and energy intakes. Am J Clin Nutr 1998; 68: 282-290.

13 Faulkner GP, Pourshahidi LK, Wallace JMW, Kerr MA, McCaffrey TA, Livingstone MBE. Perceived 'healthiness' of foods can influence consumers' estimations of energy density and appropriate portion size. Int J Obes 2014; 38: 106-112.
14 Caputo FA, Mattes RD. Human dietary responses to perceived manipulation of fat content in a midday meal. Int J Obes Relat Metab Disord 1993; 17: 237-240.

15 De Graaf C, De Jong LS, Lambers AC. Palatability affects satiation but not satiety. Physiol Behav 1999; 66: 681-688.

16 Yeomans MR. Palatability and the microstructure of feeding in humans: the appetizer effect. Appetite 1996; 27: 119-133.

17 Blundell JE, Hill AJ. Paradoxical effects of an intense sweetener (aspartame) on appetite. Lancet 1986; 327: 1092-1093.

18 Blundell JE, Rogers PJ, Hill AJ. Uncoupling sweetness and calories: methodological aspects of laboratory studies on appetite control. Appetite 1988; 11: $54-61$.

19 Swithers SE, Martin AA, Clark KM, Laboy AF, Davidson TL. Body weight gain in rats consuming sweetened liquids. Effects of caffeine and diet composition. Appetite 2010; 55: 528-533.

20 Tordoff MG. How do non-nutritive sweeteners increase food intake? Appetite 1988; 11: 5-11.

21 Benton D. Can artificial sweeteners help control body weight and prevent obesity? Nutr Res Rev 2005; 18: 63-76.

22 Duffy VB, Anderson GH. Position of the American Dietetic Association: use of nutritive and nonnutritive sweeteners. J Am Diet Assoc 1998; 98: 580-587.

23 Foreyt J, Kleinman R, Brown RJ, Lindstrom R. The use of low-calorie sweeteners by children: implications for weight management. J Nutr 2012; 142: 1155S-1162S.

24 Gardner C. Non-nutritive sweeteners: evidence for benefit vs. risk. Curr Opin Lipidol 2014; 25: 80-84.

25 Raben A, Richelsen B. Artificial sweeteners: a place in the field of functional foods? Focus on obesity and related metabolic disorders. Curr Opin Clin Nutr Metab Care 2012; 15: 597-604.

26 Brown RJ, Banate M, Rother KI. Artificial sweeteners: a systematic review of metabolic effects in youth. Int J Pediatr Obes 2010; 5: 305-312.

27 Daniels MC, Popkin BM. Impact of water intake on energy intake and weight status: a systematic review. Nutr Rev 2010; 68: 505-521.

28 de la Hunty A, Gibson S, Ashwell M. A review of the effectiveness of aspartame in helping with weight control. Nutr Bull 2006; 31: 115-128.

29 Dennis EA, Flack KD, Davy BM. Beverage consumption and adult weight management: a review. Eating Behav 2009; 10: 237-246.

30 Wiebe N, Padwal R, Field C, Marks S, Jacobs R, Tonelli M. A systematic review on the effect of sweeteners on glycemic response and clinically relevant outcomes. BMC Med 2011; 9: 123.

31 Abu-Taweel GM, Zyadah MA, Ajarem JS, Ahmad M. Cognitive and biochemical effects of monosodium glutamate and aspartame, administered individually and in combination in male albino mice. Neurotoxicol Teratol 2014; 42: 60-67.

32 Anderson RL. Response of male rats to sodium saccharin ingestion: urine composition and mineral balance. Food Cosmet Toxicol 1979; 17: 195-200.

33 Andrejic B, Mijatovic V, Calasan J, Horvat O, Samojlik I. Influence of saccharin on changes in rat pancreas and liver histol, glycaemia, food intake and weight. J Comp Pathol 2010; 143: 344.

34 Bailey CJ, Day C, Knapper JM, Turner SL, Flatt PR. Antihyperglycaemic effect of saccharin in diabetic ob/ob mice. Br J Pharmacol 1997; 120: 74-78.

35 Beck B, Burlet A, Max JP, Stricker-Krongrad A. Effects of long-term ingestion of aspartame on hypothalamic neuropeptide $Y$, plasma leptin and body weight gain and composition. Physiol Behav 2002; 75: 41-47.

36 Bergheim I, Weber S, Vos M, Krämer S, Volynets V, Kaserouni S et al. Antibiotics protect against fructose-induced hepatic lipid accumulation in mice: role of endotoxin. J Hepatol 2008; 48: 983-992.

37 Brantom PG, Gaunt IF, Grasso P. Long-term toxicity of sodium cyclamate in mice. Food Cosmet Toxicol 1973; 11: 735-746.

38 Brathwaite WA, Casterton PL, Nikiforov Al, Rihner MO, Sloter ED, Hlywka JJ. A dietary embryo/fetal developmental toxicity study of arruva, an R,R-monatin salt isomer, in Crl: CD (SD) rats. Food Chem Toxicol 2013; 62: 68-75.

39 Curry LL, Roberts A. Subchronic toxicity of rebaudioside A. Food Chem Toxicol 2008; 46: S11-S20.

40 Dalderup LM, Visser W. Effects of sodium cyclamate on the growth of rats compared with other variations in the diet. Nature 1969; 221: 91-92.

41 Dalderup LM, Visser W. Influence of extra sucrose, fats, protein and of cyclamate in the daily food on the life-span of rats. Experientia 1971; 27: 519-521.

42 Dyrskog SEU, Jeppesen PB, Colombo M, Abudula R, Hermansen K. Preventive effects of a soy-based diet supplemented with stevioside on the development of the metabolic syndrome and type 2 diabetes in Zucker diabetic fatty rats. Metabolism 2005; 54: 1181-1188.

43 Figlewicz DP, loannou G, Bennett Jay J, Kittleson S, Savard C, Roth CL. Effect of moderate intake of sweeteners on metabolic health in the rat. Physiol Behav 2009; 98: 618-624. 
44 Fisher MJ, Sakata T, Tibbels TS, Smith RA, Patil K, Khachab M et al. Effect of sodium saccharin and calcium saccharin on urinary parameters in rats fed Prolab 3200 or AIN-76 diet. Food Chem Toxicol 1989; 27: 1-9.

45 Friedhoff R, Simon JA, Friedhoff AJ. Sucrose solution vs. no-calorie sweetener vs. water in weight gain. J Am Diet Assoc 1971; 59: 485-486.

46 Fulop I, Bobes D, Croitoru D, Barbu C. influence of sugars and sweeteners on mouse body weight, stress-induced body weight changes and life expectancy. Farmacia 2014; 62: 376-389.

47 Geeraert B, Crombe F, Hulsmans M, Benhabiles N, Geuns JM, Holvoet P. Stevioside inhibits atherosclerosis by improving insulin signaling and antioxidant defense in obese insulin-resistant mice. Int J Obes 2009; 34: 569-577.

48 Goldsmith LA. Acute and subchronic toxicity of sucralose. Food Chem Toxicol 2000; 38: 53-69.

49 Higginbotham JD, Snodin DJ, Eaton KK, Daniel JW. Safety evaluation of thaumatin (talin protein). Food Chem Toxicol 1983; 21: 815-823.

50 Hlywka J, Brathwaite WA, Rihner MO, Nikiforov Al, Eapen AK. A 90-day oral (dietary) toxicity study of the 2R,4R-isomer of monatin salt in SpragueDawley rats. Food Chem Toxicol 2011; 49: 3249-3257.

51 Ishii H, Koshimizu T, Usami S, Fujimoto T. Toxicity of aspartame and its diketopiperazine for Wistar rats by dietary administration for 104 weeks. Toxicol 1981; 21: 91-94.

52 Jeppesen PB, Gregersen S, Rolfsen SED, Jepsen M, Colombo M, Agger A et al. Antihyperglycemic and blood pressure-reducing effects of stevioside in the diabetic Goto-Kakizaki rat. Metabolism 2003; 52: 372-378.

53 Jürgens $H$, Haass W, Castaneda TR, Schürmann A, Koebnick C, Dombrowski $F$ et al. Consuming fructose-sweetened beverages increases body adiposity in mice. Obesity Res 2005; 13: 1146-1156.

54 Lina BAR, Bos-Kuijpers MHM, Til HP, Bär A. Chronic toxicity and carcinogenicity study of erythritol in rats. Regul Toxicol Pharmacol 1996; 24: S264-S279.

55 Mitsutomi K, Masaki T, Shimasaki T, Gotoh K, Chiba S, Kakuma T et al. Effects of a nonnutritive sweetener on body adiposity and energy metabolism in mice with diet-induced obesity. Metabolism 2014; 63: 69-78.

56 Munro IC, Moodie CA, Krewski D, Grice HC. A carcinogenicity study of commercial saccharin in the rat. Toxicol Appl Pharmacol 1975; 32: 513-526.

57 Nikiforov Al, Eapen AK. A 90-day oral (dietary) toxicity study of rebaudioside A in Sprague-Dawley rats. Int J Toxicol 2008; 27: 65-80.

58 Nikiforov Al, Rihner MO, Eapen AK, Thomas JA. Metabolism and Toxicity Studies Supporting the Safety of Rebaudioside D. Int J Toxicol 2013; 32: 261-273.

59 Oser BL, Carson S, Cox GE, Vogin EE, Sternberg SS. Chronic toxicity study of cyclamate: saccharin (10: 1) in rats. Toxicol 1975; 4: 385-386.

60 Otabe A, Fujieda T, Masuyama T. Chronic toxicity and carcinogenicity of N-N-[3-(3-hydroxy-4-methoxyphenyl) propyl]-alpha-aspartyl]-I-phenylalanine 1-methyl ester, monohydrate (advantame) in the rat. Food Chem Toxicol 2011; 49: S35-S48.

61 Otabe A, Fujieda T, Masuyama T. A two-generation reproductive toxicity study of the high-intensity sweetener advantame in CD rats. Food Chem Toxicol 2011; 49: S70-S76.

62 Palmnas MS, Cowan TE, Bomhof MR, Su J, Reimer RA, Vogel HJ et al. Low-dose aspartame consumption differentially affects gut microbiota-host metabolic interactions in the diet-induced obese rat. PloS One 2014; 9: e109841.

63 Park J, Cha Y-S. Stevia rebaudiana Bertoni extract supplementation improves lipid and carnitine profiles in C57BL/6J mice fed a high-fat diet. J Sci Food Agric 2010; 90: 1099-1105.

64 Polyák E, Gombos K, Hajnal B, Bonyár-Müller K, Szabó S, Gubicskó-Kisbenedek A et al. Effects of artificial sweeteners on body weight, food and drink intake. Acta Physiologica Hungarica 2010; 97: 401-407.

65 Reis TA, Goulart P, de Oliveira RME, Oliveira Ld, de Abreu PS, Azevedo Ad. Metabolic parameters of wistar rats subjected to diet supplemented with stevia and sugar. Semina: Ciéncias Agrarias (Londrina) 2011; 32: 1477-1488.

66 Schoenig GP, Goldenthal El, Geil RG, Frith CH, Richter WR, Carlborg FW. Evaluation of the dose response and in utero exposure to saccharin in the rat. Food Chem Toxicol 1985; 23: 475-490.

67 Tago K, Naito Y, Nagata T, Morimura T, Furuya M, Seki T et al. A ninety-day feeding, subchronic toxicity study of oligo-N-acetylglucosamine in Fischer 344 rats. Food Chem Toxicol 2007; 45: 1186-1193.

68 Til HP, Modderman J. Four-week oral toxicity study with erythritol in rats. Regul Toxicol Pharmacol 1996; 24: S214-S220.

69 Til HP, Kuper CF, Falke HE, Bär A. Subchronic oral toxicity studies with erythritol in mice and rats. Regul Toxicol Pharmacol 1996; 24: S221-S231.

70 Waalkens-Berendsen DH, Kuilman-Wahls MEM, Bär A. Embryotoxicity and teratogenicity study with neohesperidin dihydrochalcone in rats. Regul Toxicol Pharmacol 2004; 40: 74-79.

71 Watkins AL, Williams L, Carroll C. Influence of saccharin on growth and tissue lipids in rats fed different fats and carbohydrates. Nutr Rep Int 1980; 21: 329-339.
72 Xili L, Chengjiany B, Eryi X, Reiming S, Yuengming W, Haodong S et al. Chronic oral toxicity and carcinogenicity study of stevioside in rats. Food Chem Toxicol 1992; 30: 957-965.

73 Yagi K, Matsuo T. The study on long-term toxicity of D-psicose in rats. J Clin Biochem Nutr 2009; 45: 271-277.

74 Lina BAR, Dreef-van der Meulen H, Leegwater DC. Subchronic (13-week) oral toxicity of neohesperidin dihydrochalcone in rats. Food Chem Toxicol 1990; 28: 507-513.

75 Park JS, Yoo SB, Kim JY, Lee SJ, Oh SB, Kim JS et al. Effects of saccharin intake on hippocampal and cortical plasticity in juvenile and adolescent rats. Korean $J$ Physiol Pharmacol 2010; 14: 113-118.

76 Renwick AG. The intake of intense sweeteners - an update review. Food Addit Contam 2006; 23: 327-338.

77 EFSA. EFSA Panel on Food Additives and Nutrient Sources added to food. Scientific opinion on the safety of steviol glycosides for the proposed uses as a food additive. EFSA J 2010; 8: 1-84.

78 D'Anci KE, Kanarek RB, Marks-Kaufman R. Beyond sweet taste: saccharin, sucrose, and polycose differ in their effects upon morphine-induced analgesia. Pharmacol Biochem Behav 1997; 56: 341-345.

79 D'Anci KE. Tolerance to morphine-induced antinociception is decreased by chronic sucrose or polycose intake. Pharmacol Biochem Behav 1999; 63: 1-11.

80 de Matos F, Ballard CR, Foletto KC, Batista BAM, Neves AM, Ribeiro MFM et al. Saccharin and aspartame, compared with sucrose, induce greater weight gain in adult Wistar rats, at similar total caloric intake levels. Appetite 2013; 60: 203-207.

81 Kanarek RB, White ES, Biegen MT, Marks-Kaufman R. Dietary influences on morphine-induced analgesia in rats. Pharmacol Biochem Behav 1991; 38: 681-684.

82 Kanarek RB, Przypek J, D'Anci KE, Marks-Kaufman R. Dietary modulation of mu and kappa opioid receptor-mediated analgesia. Pharmacol Biochem Behav 1997; 58: 43-49.

83 Kanarek RB, Mathes WF, Heisler LK, Lima RP, Monfared LS. Prior exposure to palatable solutions enhances the effects of naltrexone on food intake in rats. Pharmacol Biochem Behav 1997; 57: 377-381.

84 Kanarek RB, Homoleski B. Modulation of morphine-induced antinociception by palatable solutions in male and female rats. Pharmacol Biochem Behav 2000; 66: 653-659.

85 Porikos KP, Koopmans HS. The effect of non-nutritive sweeteners on body weight in rats. Appetite 1988; 11: 12-15.

86 Ramirez I. Stimulation of energy intake and growth by saccharin in rats. J Nutr 1990; 120: 123-133.

87 Yeomans MR, Clifton PG. Exposure to sweetened solutions enhances the anorectic effect of naloxone but not d-fenfluramine. Physiol Behav 1997; 62: 255-262.

88 Davidson TL, Martin AA, Clark K, Swithers SE. Intake of high-intensity sweeteners alters the ability of sweet taste to signal caloric consequences: implications for the learned control of energy and body weight regulation. Q J Exp Psychol 2011; 64: $1430-1441$

89 Swithers SE, Davidson TL. A role for sweet taste: calorie predictive relations in energy regulation by rats. Behav Neurosci 2008; 122: 161-173.

90 Swithers SE, Baker CR, Davidson TL. General and persistent effects of highintensity sweeteners on body weight gain and caloric compensation in rats. Behav Neurosci 2009; 123: 772-780.

91 Swithers SE, Laboy AF, Clark K, Cooper S, Davidson TL. Experience with the highintensity sweetener saccharin impairs glucose homeostasis and GLP-1 release in rats. Behav Brain Res 2012; 233: 1-14.

92 Swithers SE, Sample CH, Davidson TL. Adverse effects of high-intensity sweeteners on energy intake and weight control in male and obesity-prone female rats. Behav Neurosci 2013; 127: 262-274.

93 Swithers SE, Sample CH, Katz DP. Influence of ovarian and non-ovarian estrogens on weight gain in response to disruption of sweet taste-calorie relations in female rats. Horm Behav 2013; 63: 40-48.

94 Berkey CS, Rockett HR, Field AE, Gillman MW, Colditz GA. Sugar-added beverages and adolescent weight change. Obes Res 2004; 12: 778-788.

95 Chen L, Appel LJ, Loria C, Lin PH, Champagne CM, Elmer PJ et al. Reduction in consumption of sugar-sweetened beverages is associated with weight loss: the PREMIER trial. Am J Clin Nutr 2009; 89: 1299-1306.

96 Duffey KJ, Steffen LM, Van Horn L, Jacobs DR, Popkin BM. Dietary patterns matter: diet beverages and cardiometabolic risks in the longitudinal Coronary Artery Risk Development in Young Adults (CARDIA) Study. Am J Clin Nutr 2012; 95: 909-915.

97 Laska MN, Murray DM, Lytle LA, Harnack LJ. Longitudinal associations between key dietary behaviors and weight gain over time: transitions through the adolescent years. Obesity 2012; 20: 118-125.

98 Ludwig DS, Peterson KE, Gortmaker SL. Relation between consumption of sugarsweetened drinks and childhood obesity: a prospective, observational analysis. Lancet 2001; 357: 505-508. 
99 Nettleton JA, Lutsey PL, Wang Y, Lima JA, Michos ED, Jacobs DR. Diet soda intake and risk of incident metabolic syndrome and type 2 diabetes in the Multi-Ethnic Study of Atherosclerosis (MESA). Diabetes Care 2009; 32: 688-694.

100 Pan A, Malik VS, Hao T, Willett WC, Mozaffarian D, Hu FB. Changes in water and beverage intake and long-term weight changes: results from three prospective cohort studies. Int J Obes 2013; 37: 1378-1385.

101 Striegel-Moore RH, Thompson D, Affenito SG, Franko DL, Obarzanek E, Barton BA et al. Correlates of beverage intake in adolescent girls: the National Heart, Lung, and Blood Institute Growth and Health Study. J Pediatr 2006; 148: 183-187.

102 Vanselow MS, Pereira MA, Neumark-Sztainer D, Raatz SK. Adolescent beverage habits and changes in weight over time: findings from Project EAT. Am J Clin Nutr 2009; 90: 1489-1495.

103 Cecil JE, Palmer CN, Wrieden W, Murrie I, Bolton-Smith C, Watt P et al. Energy intakes of children after preloads: adjustment, not compensation. Am J Clin Nutr 2005; 82: 302-308

104 Akhavan T, Luhovyy BL, Anderson GH. Effect of drinking compared with eating sugars or whey protein on short-term appetite and food intake. Inter $J$ Obes 2010; 35: 562-569.

105 Akhavan T, Anderson GH. Effects of glucose-to-fructose ratios in solutions on subjective satiety, food intake, and satiety hormones in young men. Am J Clin Nutr 2007; 86: 1354-1363.

106 Anderson GH, Saravis S, Schacher R, Zlotkin S, Leiter LA. Aspartame: effect on lunch-time food intake, appetite and hedonic response in children. Appetite 1989; 13: 93-103.

107 Anton SD, Martin CK, Han H, Coulon S, Cefalu WT, Geiselman P et al. Effects of stevia, aspartame, and sucrose on food intake, satiety, and postprandial glucose and insulin levels. Appetite 2010; 55: 37-43.

108 Appleton KM, Blundell JE. Habitual high and low consumers of artificiallysweetened beverages: effects of sweet taste and energy on short-term appetite. Physiol Behav 2007; 92: 479-486.

109 Bellissimo N, Pencharz PB, Thomas SG, Anderson GH. Effect of television viewing at mealtime on food intake after a glucose preload in boys. Pediatr Res 2007; 61: 745-749.

110 Bellissimo N, Thomas SG, Goode RC, Anderson GH. Effect of short-duration physical activity and ventilation threshold on subjective appetite and short-term energy intake in boys. Appetite 2007; 49: 644-651.

111 Beridot-Therond ME, Arts I, Fantino M, de La Gueronniere V. Short-term effects of the flavour of drinks on ingestive behaviours in man. Appetite 1998; 31: 67-81.

112 Birch LL, McPhee L, Sullivan S. Children's food intake following drinks sweetened with sucrose or aspartame: time course effects. Physiol Behav 1989; 45: 387-395.

113 Black RM, Tanaka P, Leiter LA, Anderson GH. Soft drinks with aspartame: effect on subjective hunger, food selection, and food intake of young adult males. Physiol Behav 1991; 49: 803-810.

114 Black RM, Leiter LA, Anderson GH. Consuming aspartame with and without taste: differential effects on appetite and food intake of young adult males. Physiol Behav 1993; 53: 459-466.

115 Booth DCA, Chase AlLE. Temporal bounds of post-ingestive glucose induced satiety in man. Nature 1970; 228: 1104-1105.

116 Brala PM, Hagen RL. Effects of sweetness perception and caloric value of a preload on short term intake. Physiol Behav 1983; 30: 1-9.

117 Branton A, Akhavan T, Gladanac B, Pollard D, Welch J, Rossiter M et al. Pre-meal video game playing and a glucose preload suppress food intake in normal weight boys. Appetite 2014; 83: 256-262.

118 Canty DJ, Chan MM. Effects of consumption of caloric vs noncaloric sweet drinks on indices of hunger and food consumption in normal adults. Am J Clin Nutr 1991: 53: 1159-1164.

119 Carvalho P, Sousa M, Barros R, Padrao P, Moreira P, Teixeira V. Impact of morning ingestion of sugary and sweetened beverages on energy and fluid intake throughout day. Ann Nutr Metab 2013; 63: 1448-1449.

120 DellaValle DM, Roe LS, Rolls BJ. Does the consumption of caloric and non-caloric beverages with a meal affect energy intake? Appetite 2005; 44: 187-193.

121 Drewnowski A, Massien C, Louis-Sylvestre J, Fricker J, Chapelot D, Apfelbaum M. The effects of aspartame versus sucrose on motivational ratings, taste preferences, and energy intakes in obese and lean women. Int J Obes Relat Metab Disord 1994; 18: 570-578.

122 Drewnowski A, Massien C, Louis-Sylvestre J, Fricker J, Chapelot D, Apfelbaum M. Comparing the effects of aspartame and sucrose on motivational ratings, taste preferences, and energy intakes in humans. Am J Clin Nutr 1994; 59: 338-345.

123 Ford HE, Peters V, Martin NM, Sleeth ML, Ghatei MA, Frost GS et al. Effects of oral ingestion of sucralose on gut hormone response and appetite in healthy normalweight subjects. Eur J Clin Nutr 2011; 65: 508-513.

124 Gheller B, Akhavan T, Pollard D, Gladanac B, Constantino M, Luhovyy B et al. A pre-meal glucose drink, but not video game playing, suppresses food intake in overweight and obese boys (1040.8). FASEB J 2014; 28: 1040-1048.
125 Guss JL, Kissileff HR, Pi-Sunyer FX. Effects of glucose and fructose solutions on food intake and gastric emptying in nonobese women. Am J Physiol Regul Integr Comp Physiol 1994; 36: R1537.

126 Hetherington MM, Wood C, Lyburn SC. Response to energy dilution in the short term: evidence of nutritional wisdom in young children? Nutr Neurosci 2000; 3: 321-329.

127 Ho EE, Liszt AF, Pudel V. The effects of energy content and sweet taste on food consumption in restrained and non-restrained eaters. J Am Diet Assoc 1990; 90: 1223-1228.

128 Holt NS. The effects of sugar-free vs sugar-rich beverages on feelings of fullness and subsequent food intake. Int J Food Sci Nutr 2000; 51: 59-71.

$129 \mathrm{Kim}$ JY, Kissileff HR. The effect of social setting on response to a preloading manipulation in non-obese women and men. Appetite 1996; 27: 25-40.

130 King NA, Appleton K, Rogers PJ, Blundell JE. Effects of sweetness and energy in drinks on food intake following exercise. Physiol Behav 1999; 66: 375-379.

131 Lavin JH, French SJ, Read NW. The effect of sucrose-and aspartame-sweetened drinks on energy intake, hunger and food choice of female, moderately restrained eaters. Int J Obes Relat Metab Disord 1997; 21: 37-42.

132 Maersk M, Belza A, Holst JJ, Fenger-Grøn M, Pedersen SB, Astrup A et al. Satiety scores and satiety hormone response after sucrose-sweetened soft drink compared with isocaloric semi-skimmed milk and with non-caloric soft drink: a controlled trial. Eur J Clin Nutr 2012; 66: 523-529.

133 Melanson KJ, Westerterp-Plantenga MS, Campfield AL, Saris WH. Blood glucose and meal patterns in time-blinded males, after aspartame, carbohydrate, and fat consumption, in relation to sweetness perception. Br J Nutr 1999; 82: 437-446.

134 Monsivais $P$, Perrigue MM, Drewnowski A. Sugars and satiety: does the type of sweetener make a difference? Am J Clin Nutr 2007; 86: 116-123.

135 Panahi S, El Khoury D, Luhovyy BL, Goff HD, Anderson GH. Caloric beverages consumed freely at meal-time add calories to an ad libitum meal. Appetite 2013, 65: 75-82.

136 Patel BP, Bellissimo N, Thomas SG, Hamilton JK, Anderson GH. Television viewing at mealtime reduces caloric compensation in peripubertal, but not postpubertal, girls. Pediatr Res 2011; 70: 513-517.

137 Ranawana DV, Henry CJK. Are caloric beverages compensated for in the short-term by young adults? An investigation with particular focus on gender differences. Appetite 2010; 55: 137-146.

138 Reid M, Hammersley R. Effects of carbohydrate intake on subsequent food intake and mood state. Physiol Behav 1995; 58: 421-427.

139 Reid M, Hammersley R. The effects of sucrose and maize oil on subsequent food intake and mood. Br J Nutr 1999; 82: 447-455.

140 Soenen S, Westerterp-Plantenga MS. No differences in satiety or energy intake after high-fructose corn syrup, sucrose, or milk preloads. Am J Clin Nutr 2007; 86: 1586-1594.

141 Tamam S, Bellissimo N, Patel BP, Thomas SG, Anderson GH. Overweight and obese boys reduce food intake in response to a glucose drink but fail to increase intake in response to exercise of short duration. Appl Physiol Nutr Metab 2012; 37: 520-529.

142 Van Engelen M, Khodabandeh S, Akhavan T, Agarwal J, Gladanac B, Bellissimo N. Effect of sugars in solutions on subjective appetite and short-term food intake in 9-to 14-year-old normal weight boys. Eur J Clin Nutr 2014; 68: 773-777.

143 Van Wymelbeke V, Beridot-Therond ME, de La Gueronniere V, Fantino M. Influence of repeated consumption of beverages containing sucrose or intense sweeteners on food intake. Eur J Clin Nutr 2004; 58: 154-161.

144 Wilson JF. Lunch eating behavior of preschool children: effects of age, gender and type of beverage served. Physiol Behav 2000; 70: 27-33.

145 Woodend DM, Anderson GH. Effect of sucrose and safflower oil preloads on short term appetite and food intake of young men. Appetite 2001; 37: 185-195.

146 Rodin J. Comparative effects of fructose, aspartame, glucose, and water preloads on calorie and macronutrient intake. Am J Clin Nutr 1990; 51: 428-435.

147 Rogers PJ, Lambert TC, Alikanizadeh LA, Blundell JE. Intense sweeteners and appetite: responses of informed and uninformed subjects consuming food sweetened with aspartame or sugar. Int J Obes 1990; 14: 105.

148 Rogers PJ, Gadah NS, Kyle LA, Brunstrom JM. Standard preload-test meal study designs may underestimate satiety effects: sugar containing drinks as an example. Proc Nutr Soc 2011; 70: E401.

149 Rogers PJ. What is the mechanism for the postingestive anorectic effect of aspartame? Appetite 2013; 71: 485.

150 Rogers PJ, Carlyle JA, Hill AJ, Blundell JE. Uncoupling sweet taste and calories: comparison of the effects of glucose and three intense sweeteners on hunger and food intake. Physiol Behav 1988; 43: 547-552.

151 Rogers PJ, Blundell JE. Separating the actions of sweetness and calories: effects of saccharin and carbohydrates on hunger and food intake in human subjects. Physiol Behav 1989; 45: 1093-1099.

152 Rogers PJ, Pleming HC, Blundell JE. Aspartame ingested without tasting inhibits hunger and food intake. Physiol Behav 1990; 47: 1239-1243. 
153 Rogers PJ. Why a palatability construct is needed. Appetite 1990; 14: 167-170.

154 Rogers PJ, Keedwell P, Blundell JE. Further analysis of the short-term inhibition of food intake in humans by the dipeptide L-aspartyl-L-phenylalanine methyl ester (aspartame). Physiol Behav 1991; 49: 739-743.

155 Rogers PJ, Blundell JE. Reanalysis of the effects of phenylalanine, alanine, and aspartame on food intake in human subjects. Physiol Behav 1994; 56: 247-250.

156 Rogers PJ, Burley VJ, Alikhanizadeh LA, Blundell JE. Postingestive inhibition of food intake by aspartame: importance of interval between aspartame administration and subsequent eating. Physiol Behav 1995; 57: 489-493.

157 Rolls BJ, Laster LJ, Summerfelt A. Hunger and food intake following consumption of low-calorie foods. Appetite 1989; 13: 115-127.

158 Rolls BJ, Kim S, Fedoroff IC. Effects of drinks sweetened with sucrose or aspartame on hunger, thirst and food intake in men. Physiol Behav 1990; 48: 19-26.

159 Blundell J, De Graaf C, Hulshof T, Jebb S, Livingstone B, Lluch A et al. Appetite control: methodological aspects of the evaluation of foods. Obesity Rev 2010; 11: 251-270.

160 Gibson EL, Carnell S, Wardle J. Learnt satiation in effects of disguised preloads on lunch intake and appetite in preschool children. Appetite 2006; 47: 280.

161 Brunstrom JM. Associative learning and the control of human dietary behavior. Appetite 2007; 49: 268-271.

162 Hogenkamp PS, Stafleu A, Mars M, De Graaf C. Learning about the energy density of liquid and semi-solid foods. Int J Obes 2011; 36: 1229-1235.

163 Yeomans MR. Flavour-nutrient learning in humans: an elusive phenomenon? Physiol Behav 2012; 106: 345-355.

164 Kral TVE, Roe LS, Rolls BJ. Does nutrition information about the energy density of meals affect food intake in normal-weight women? Appetite 2002; 39: 137-145.

165 Sclafani A. Sweet taste signaling in the gut. Proc Natl Acad Sci USA 2007; 104: 14887-14888.

166 Brown RJ, Rother KI. Non-nutritive sweeteners and their role in the gastrointestinal tract. J Clin Endocrinol Metab 2012; 97: 2597-2605.

167 Renwick AG, Molinary SV. Sweet-taste receptors, low-energy sweeteners, glucose absorption and insulin release. Br J Nutr 2010; 104: 1415-1420.

168 Sylvetsky A, Rother Kl, Brown R. Artificial sweetener use among children: epidemiol, recommendations, metabolic outcomes, and future directions. Pediatr Clin North Am 2011; 58: 1467-1480.

169 Anderson GH, Catherine NL, Woodend DM, Wolever TM. Inverse association between the effect of carbohydrates on blood glucose and subsequent short-term food intake in young men. Am J Clin Nutr 2002; 76: 1023-1030.

170 Steinert RE, Frey F, Tõpfer A, Drewe J, Beglinger C. Effects of carbohydrate sugars and artificial sweeteners on appetite and the secretion of gastrointestinal satiety peptides. Br J Nutr 2011; 105: 1320-1328.

171 Stern SB, Bleicher SJ, Flores A, Gombos G, Recitas D, Shu J. Administration of aspartame in non-insulin-dependent diabetics. J Toxicol Environ Health A 1976; 2: 429-439.

172 Knopp RH, Brandt K, Arky RA. Effects of aspartame in young persons during weight reduction. J Toxicol Environ Health 1976; 2: 417-428.

173 Blackburn GL, Kanders BS, Lavin PT, Keller SD, Whatley J. The effect of aspartame as part of a multidisciplinary weight-control program on short-and long-term control of body weight. Am J Clin Nutr 1997; 65: 409-418.

174 Naismith DJ, Rhodes C. Adjustment in energy intake following the covert removal of sugar from the diet. J Hum Nutr Diet 1995; 8: 167-175.

175 Njike VY, Faridi Z, Shuval K, Dutta S, Kay CD, West SG et al. Effects of sugarsweetened and sugar-free cocoa on endothelial function in overweight adults. Int J Cardiol 2011; 149: 83-88.

176 Raben A, Vasilaras TH, Müller AC, Astrup A. Sucrose compared with artificial sweeteners: different effects on ad libitum food intake and body weight after 10 wk of supplementation in overweight subjects. Am J Clin Nutr 2002; 76: 721-729.

177 Reid M, Hammersley R, Hill AJ, Skidmore P. Long-term dietary compensation for added sugar: effects of supplementary sucrose drinks over a 4-week period. Br J Nutr 2007; 97: 193-203.

178 Reid M, Hammersley R, Duffy M. Effects of sucrose drinks on macronutrient intake, body weight, and mood state in overweight women over 4 weeks. Appetite 2010; 55: 130-136.

179 Tate DF, Turner-McGrievy G, Lyons E, Stevens J, Erickson K, Polzien K et al. Replacing caloric beverages with water or diet beverages for weight loss in adults: main results of the Choose Healthy Options Consciously Everyday (CHOICE) randomized clinical trial. Am J Clin Nutr 2012; 95: 555-563.

180 Tordoff MG, Alleva AM. Effect of drinking soda sweetened with aspartame or high-fructose corn syrup on food intake and body weight. Am J Clin Nutr 1990; 51: 963-969.

181 Wolraich ML, Lindgren SD, Stumbo PJ, Stegink LD, Appelbaum MI, Kiritsy MC. Effects of diets high in sucrose or aspartame on the behavior and cognitive performance of children. N Engl J Med 1994; 330: 301-307.
182 de Ruyter JC, Olthof MR, Seidell JC, Katan MB. A trial of sugar-free or sugarsweetened beverages and body weight in children. N Engl J Med 2012; 367: 1397-1406.

183 Kanders BS, Lavin PT, Kowalchuk MB, Greenberg I, Blackburn GL. An evaluation of the effect of aspartame on weight loss. Appetite 1988; 11: 73-84.

184 Maersk M, Belza A, Stødkilde-Jørgensen H, Ringgaard S, Chabanova E, Thomsen $\mathrm{H}$ et al. Sucrose-sweetened beverages increase fat storage in the liver, muscle, and visceral fat depot: a 6-mo randomized intervention study. Am J Clin Nutr 2012; 95: 283-289.

185 Peters JC, Wyatt HR, Foster GD, Pan Z, Wojtanowski AC, Vander Veur SS et al. The effects of water and non-nutritive sweetened beverages on weight loss during a 12-week weight loss treatment program. Obesity 2014; 22: $1415-1421$.

186 Ebbeling CB, Feldman HA, Osganian SK, Chomitz VR, Ellenbogen SJ, Ludwig DS. Effects of decreasing sugar-sweetened beverage consumption on body weight in adolescents: a randomized, controlled pilot study. Pediatrics 2006; 117: 673-680.

187 Ebbeling CB, Feldman HA, Chomitz VR, Antonelli TA, Gortmaker SL, Osganian SK et al. A randomized trial of sugar-sweetened beverages and adolescent body weight. N Engl J Med 2012; 367: 1407-1416.

188 Munsters MJ, Saris WH. The effect of sugar-sweetened beverage intake on energy intake in an ad libitum 6-month low-fat high-carbohydrate diet. Ann Nutr Metab 2010; 57: 116-123.

189 Stookey JD, Constant F, Gardner CD, Popkin BM. Replacing sweetened caloric beverages with drinking water is associated with lower energy intake. Obesity 2007; 15: 3013-3022.

190 Williams CL, Strobino BA, Brotanek J. Weight control among obese adolescents: a pilot study. Int J Food Sci Nutr 2007; 58: 217-230.

191 Levitsky DA. The non-regulation of food intake in humans: hope for reversing the epidemic of obesity. Physiol Behav 2005; 86: 623-632.

192 Mattes RD, Pierce CB, Friedman MI. Daily caloric intake of normal-weight adults: response to changes in dietary energy density of a luncheon meal. Am J Clin Nutr 1988; 48: 214-219.

193 Miller P, Perez V. Low-calorie sweeteners and body weight and composition: a meta-analysis of randomized controlled trials and prospective cohorts (391.1). FASEB J 2014; 28: 391.

194 Swithers SE, Martin AA, Davidson TL. High-intensity sweeteners and energy balance. Physiol Behav 2010; 100: 55-62.

195 Viskaal-Van Dongen M, Van Den Berg M, Vink N, Kok FJ, De Graaf C. Taste-Nutrient relations in commonly consumed foods. Appetite 2011; 57: 567.

196 Bray GA, Nielsen SJ, Popkin BM. Consumption of high-fructose corn syrup in beverages may play a role in the epidemic of obesity. Am J Clin Nutr 2004; 79: 537-543.

197 Willett WC, Ludwig DS. Science souring on sugar. BMJ 2013; 346: e8077.

198 Ventura AK, Mennella JA. Innate and learned preferences for sweet taste during childhood. Curr Opin Clin Nutr Metab Care 2011; 14: 379-384.

199 Weenen H, Stafleu A, De Graaf C. Dynamic aspects of liking: post-prandial persistence of sensory specific satiety. Food Qual Prefer 2005; 16: 528-535.

200 Snoek HM, Huntjens L, van Gemert LJ, De Graaf C, Weenen H. Sensory-specific satiety in obese and normal-weight women. Am J Clin Nutr 2004; 80: 823-831.

201 Griffioen-Roose S, Finlayson G, Mars M, Blundell JE, De Graaf C. Measuring food reward and the transfer effect of sensory specific satiety. Appetite 2010; 55: 648-655.

202 Piernas C, Tate DF, Wang X, Popkin BM. Does diet-beverage intake affect dietary consumption patterns? Results from the Choose Healthy Options Consciously Everyday (CHOICE) randomized clinical trial. Am J Clin Nutr 2013; 97: 604-611.

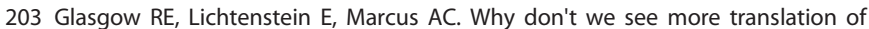
health promotion research to practice? Rethinking the efficacy-to-effectiveness transition. Am J Public Health 2003; 93: 1261-1267.

204 Te Morenga L, Mallard S, Mann J. Dietary sugars and body weight: systematic review and meta-analyses of randomised controlled trials and cohort studies. BMJ 2013; 346: e7492.

205 Malik VS, Schulze MB, Hu FB. Intake of sugar-sweetened beverages and weight gain: a systematic review. Am J Clin Nutr 2006; 84: 274-288.

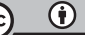

This work is licensed under a Creative Commons Attribution 4.0 International License. The images or other third party material in this article are included in the article\#amp;\#x02019;s Creative Commons license, unless indicated otherwise in the credit line; if the material is not included under the Creative Commons license, users will need to obtain permission from the license holder to reproduce the material. To view a copy of this license, visit http://creativecommons.org/ licenses/by/4.0/

Supplementary Information accompanies this paper on International Journal of Obesity website (http://www.nature.com/ijo) 